\begin{tabular}{c|c|c|c|c|c|} 
DOI: http://dx.doi.org/10.54085/ap.covid19.2021.10.2.3 \\
Annals of Phytomedicine: An International Journal \\
http://www.ukaazpublications.com/publications/index.php \\
Print ISSN : 2278-9839 Online ISSN : 2393-9885
\end{tabular}

\title{
Significance of nuts in strengthening immune system during COVID-19
}

\author{
Indhuleka , R. Sanjana*, J. Janet and V. Ragavi \\ Department of Science and Humanities, Sri Krishna College of Engineering and Technology, Coimbatore-641008, Tamilnadu, India \\ *Department of Business Management, Sheffield Hallam University, Sheffield, United Kingdom
}

\section{Article Info}

Article history

Received 25 August 2021

Revised 15 Ocotber 2021

Accepted 16 Ocotber 2021

Published Online 30 December 2021

\section{Keywords}

COVID-19

Immunomodulatory

Immunity

Balanced diet

Nutrients

\begin{abstract}
Viral infections are contagious and deadly. Many viral attacks in the past decades including COVID-19 have turned into pandemics and cost millions of lives. Treatment to virus is difficult as they transform themselves into many variants. Thus, an intelligent way of keeping oneself out of the trouble is through better nutrition that enhance immune responses. Foods that provide high quantities of nutrients are vegetables, fruits and nuts. They are rich in fibres, fats, protein, vitamins, minerals and plant bioactive compounds like phytosterols, polyphenolics, flavonoids, etc. Many studies and randomised control trials have proven their therapeutic effects and health promoting capacities. These compounds interfere with the pathways of metabolic mechanisms in the human body and work by either providing a protective scope or by destroying any harmful incomings into the body; that would disrupt the homeostasis. In this article, nuts and their nutritive components that administer healthy benefits are discussed. Almonds, cashew nuts, pistachios, peanuts, chestnuts and Brazil nuts are examined and reviewed here. The nutritional composition of these nuts and their mechanism to offer medicinal properties are explained in detail. Apart from nutritional values, these nuts are rich source of antioxidants that confer anti-inflammatory and immunomodulatory features. These activities enhance the immune responses by activating the defense mechanisms. Apart from the intake of highly nutritious diet, practising social distancing, isolation and better sanitation procedures are highly beneficial to avoid the severity of the viral attacks.
\end{abstract}

\section{Introduction}

\subsection{Coronavirus}

Coronavirus (COVID-19), a worldwide pandemic has costed many lives. It is caused by the novel coronavirus SARS-CoV-2, which belong to the Coronaviridae virus family. The first case of this virus was found in Wuhan, China in 2019; among the patients with pneumonia symptoms (Shakoor et al., 2021). Similar kinds of virus from same family have caused diseases like SARS (Severe Acute Respiratory Syndrome) and MERS (Middle East Acute Respiratory Syndrome) in 2002 and 2011, respectively. Paules et al. (2020) stated that virus transmitted from animal to human in the first place, making it a zoonotic transmission; which then got transferred from humans-tohumans through physical contact and other physical activities like coughing and sneezing, etc. The general symptoms of this disease are fever, cough, headache, respiratory disorders, pneumonia, etc. It keeps evolving as the virus variant evolves. About $80 \%$ of the affected patients suffer from moderate symptoms, while around $14 \%$ and $6 \%$ patients suffer from severe and critical symptoms, respectively (Alagawany et al., 2021). The pathogenesis of the COVID-19 virus was explained by Mason (2020) in three steps. The first step is

Corresponding author: Dr. Indhuleka
Professor, Department of Science and Humanities, Sri Krishna College
of Engineering and Technology, Coimbatore-641008, Tamilnadu,
India
E-mail: indhuleka@gmail.com
Tel.: +91-9944633778

Copyright () 2021 Ukaaz Publications. All rights reserved.

Email: ukaaz@yahoo.com; Website: www.ukaazpublications.com usually asymptomatic. Initially, the point of entry of the virus is through nasal cavity where it attaches to the epithelial cells and replicates. The second step is to enter the site of action, lungs through the respiratory tract which brings the onset of moderate symptoms. During the third step, the virus replicates manifold and transmits to the target organs, thereby completing the development of the disease by showing severe symptoms. It is reported that $80 \%$ of the people affected by coronavirus suffer from very moderate symptoms that does not need hospital care (Leung et al., 2003). But, old age and poor immune system contribute to worsening conditions along with severe to critical symptoms. Studies also show that patients with medical history of cardiovascular diseases, diabetes, pulmonary and respiratory disorders and obesity are more vulnerable to the virus. (mortality rate-49\%-China CDC-Centres for Disease Control and Prevention) (Wang et al., 2020).

\subsection{Development of immune system through nutrition}

A good immune system has the ability to counteract the harmful effects of the disease. Immune system is the most important functioning to fight infection and viral diseases like coronavirus as it gets activated when a foreign particle enters the human body and starts its action against it (Indhuleka et al., 2020). Research evidence suggests that nutritional interventions plays an important role in COVID-19 management and treatment. WHO (World Health Organisation) reports that a balanced diet contribute to an efficient working of the immune system. This diet comprises a good load of vitamins, minerals, carbohydrates, polysaccharides, lipids, fibres, other essential macro and micronutrients (Chowdhury et al., 2020). The virus affects lungs, liver, kidney causing fatal conditions 
Nutrients that perform immunemodulatory functions along with powerful antioxidant properties are necessary to combat this disease. Protein rich foods provide antiviral activities. Vitamin B protects the body from infection while vitamin $\mathrm{C}$ provides protection against flu-like symptoms (Wessling-Resnick, 2018). Vitamins A, D and E are equally important in protection against COVID-19. Minerals like zinc, copper, selenium improves the functioning of immune system. Foods like fruits, vegetables, legumes, nuts, whole grains offer these nutrient in abundance. Apart from these nutrients, many phytochemicals and functional foods have shown to be important in improving the immune functions. The beneficial impact of these nutrients decreases the threat of serious illness and death.

\section{Immunomodulatory functions of nutrients}

\subsection{Polysaccharides}

Polysaccharides are essential macromolecules formed with many monosaccharaides linked together through gylocosidic bonds. They possess many health giving properties like immunomodulatory activities and antioxidative properties which makes it an important constituent to boost the immune system (Chang et al., 2015). Chen and Huang (2018) reported that these polysaccharides with phenolics and protein show antiviral activities against influenza, herpes simplex virus, human immunodeficiency hepatitis virus, etc. $\beta$-glucan is one such dietary polysaccharide that has the ability to destroy the viral substances by producing cytokines and activating the immune cells (T lymphocytes, natural killer cells and dendritic cells) of the host; showing its antiviral capabilities (Urbancikova et al., 2020). Several studies suggest that $\beta$-glucan acts as an immunomodulatory agent in various diseases like HIV infection, influenza, cancer, etc. (Thirumdas et al., 2021). Fructans are another group of polysaccharides that show beneficial activity according to the chain of the fructose groups. Toll-like receptors (TLR) in these fructans work on initiating innateimmunity as an armour against both viral and bacterial diseases. Research conducted by Kumar et al. (2015) on rats showed antiviral and immunomodulatory functions in the fructans by producing nitric oxide which in turn stimulated the interleukins, interferon-gamma and tumour necrosis factors. Sulphated polysaccharides are another group of polysaccharides that shows therapeutic attributes against many viruses including HIV, rotavirus, etc. These sulphated polysaccharides provide a protection like cover against the virus, thereby preventing the adsorption of the viral matter into the host (He et al., 2020). This action produces the immune cells (macrophages, lymphocytes, etc.), immune-stimulatory particles, nitric oxide. These actions on-course destroy the virus and improves the immunity to the host.

\subsection{Proteins}

Lectin and lactoferrin are a group of proteins that has antiviral capacity. Lectins are glycan-binding proteins that acts on innate immunity, thereby improving immune responses during bacterial and viral infections. Lectin interacts with the viral surface with sugar and shows their antiviral activity (Singh et al., 2020). Another mode of action is by immunomodulatory functions through IL-1 $\beta$, TNF $\alpha$ and INFy (Sabater-Molina et al., 2009). Lectins have proven to be effective against HIV, influenza and coronaviruses (Hwang et al., 2020). Lactoferrins are group of proteins that bind to iron. This molecule enhances the innate immunity. They produce cytokines, T-helper cells. The mode of action of lactoferrin is by interfering with the adsorption process of the virus on the host and also activating the $\mathrm{T}$ helper cells, natural killer cells (Wakabayashi et al., 2014). Also lactoferrins possess iron that act as antioxidants.

\subsection{Lipids}

Some fatty acid increases the immunity in the host by inactivating the microbes. Studies by Das (2018) suggest that PUFA lyse the microbe's membranes which constrain the viral replication. Omega3-fatty acids have metabolites that improves immune functions on this basis. Lipoxin is bioactive form of arachidonic acid that enhances the defense activities of the host, thereby improving the immune reactions. Medium chain fatty acids like palmitic, palmitoleic and lauric acids offer antiviral activity (Park and Gallagher, 2017). Lipids also contribute to anti-inflammatory actions and act as antimicrobial agents.

\subsection{Minerals}

\subsubsection{Zinc}

Zinc is one of the most important minerals to improve the immunity in human body. It especially controls the innate immunity by producing antibodies, as well as interfering in the signalling pathways of both specific and non-specific immunity (Wessels et al., 2017). Zinc acts as immunomodulatory agent, antioxidant, antiviral agent and anti-inflammatory agent (Alroy et al., 1995). Immune activities including the production of monocytes, natural killer cells and interferons are enhanced in the presence of zinc (Gombart et al., 2020). Functioning of immune cells like neutrophils, T cells, B cells, macrophages, etc., are supervised by zinc. Zinc also acts as a cofactor for antioxidants like superoxide dismutase and establishes its antioxidant activities in reactions involving stabilisation of sulphydryls against oxidation and reducing the oxidative injuries. It also increases the NF- $\kappa \mathrm{B}$ activation improving the immune functions (Jarosz et al., 2017). Zinc induces the production of a sulphydryl rich protein called metallothionein that reduces free radical damages of the cell. This protein also acts as an intracellular sensor detecting oxidative stress, thereby regulating immune functions (Gupta et al., 2019). Zinc is said to provide protection against respiratory diseases like pneumonia, influenza, common cold, etc., also against viral infections like HIV, Hepatitis C, Herpes, SARS, etc. (Thirumdas et al., 2021). Depletion of zinc in the patient's body makes them exposed to infectious diseases due to bacteria, virus, fungus, etc. (Karacabey and Ozdemir, 2020). Zinc deficiency has proven to cause disturbance in the homeostasis of immune responses that leads to abnormal lymphopoieses, affects the intercellular cytokine signalling which ultimately depress the immune response (Maares and Haase, 2016). It also affects the lung tissues by increasing the pro-inflammatory cytokines. Zinc supplementation enhances the expressions of IL-2 and IL-2R- $\alpha$ mRNA. It also increases the concentration of natural killer cells, T-cells, etc. Randomised control trials conducted to study the effect of zinc supplementation shows imcreased cytokine responses, CD4+T cells (Jayawardena et al., 2020). Research conducted by (Barnett et al., 2016) shows that supplementation of zinc $30 \mathrm{mg} / \mathrm{day}$ for 3 months increased the concentration of T-cells in serum. In the context of COVID-19; zinc ions interact with zinc ionophorepyrithione and curb the viral replication. Chloroquine has antiviral activity that possess zinc. Studies suggest increasing the concentration of zinc in the same increases its antiviral activity (Skalny et al., 2020). Other ways of destructing the COVID-19 virus is by targeting the zinc ions of the virus with the zinc ions of the antiviral drug disulphiram making it inactive (Lin et al., 2018). Zinc supplementation for COVID-19 patients have recorded lesser damage due to respiratory infections. 


\subsubsection{Iron}

Iron is involved with innate immune responses of the human body. It acts by interacting with other life-substances forming metalenzymes and protein like iron catalases and lactoferrin (an iron chelated protein that acts as first line of defense), respectively that enhances the immunity (Fatima et al., 2020). Iron is required in the working of DNA synthesis, DNA repair, regulation of gene expression, cell proliferation and respiration and other important activities like maturation of lymphocytes to regulate immune functions. $\mathrm{T}$ cells differentiation and production of cytokines are looked after by iron (Gombart et al., 2020). Iron deficiency causes respiratory disorders. But, iron is also an important source of viral replication. Thus, overdose of iron have shown to cause viral infection (Luo et al., 2020). High levels of iron in serum contribute to hepatitis B virus, HIV, etc. This can be overcome by using iron-chelating to interact with free iron and making them unavailable for viral replication (Luo et al., 2020).

\subsubsection{Copper}

Copper plays a vital role in maintaining the immune system of our body. Copper possess antiviral and antibacterial properties (Jayawardena et al., 2020). Increasing copper intake to $7.8 \mathrm{mg} /$ day improved the antioxidation status, and thus immune function. Copper also chelates with thujaplicin that restricts the viral replication of influenza. Copper in its ionic form involves in redox reaction that creates holes in the viral membrane leading to the destruction of its genetic material (Thirumdas et al., 2021). Copper ions perform virucidal actions against virus like herpes that damages the virus by causing oxidative damages (Vincent $e t$ al., 2018). Copper also acts as an antioxidant by reacting with superoxide dismutase. It also produces $\mathrm{T}$ cells, natural killer cells, neutrophils, macrophages, etc., which enhances the immune functioning. Copper acts as anti-inflammatory agent too.

\subsubsection{Selenium}

Selenium is a trace element that possesses anti-inflammatory activity and antioxidant attributes. The antioxidant property of selenium is attributed to the selenoprotein enzymes (Kieliszek, 2019). These proteins also ensures the production of interferon. Selenium when supplemented with 50-100 $\mu \mathrm{g} /$ day elevated the plasma levels which improved the immune functioning by increasing the immune responses through increased levels of IFN- $\gamma$, IL-8 and IL-10, T-cells, NK cells. When supplemented with $200 \mu \mathrm{g} /$ day, selenoproteins show virucidal actions (Gombart et al., 2020). The mechanism of selenium against virus is by reducing the oxidative damage and increasing the production of $\mathrm{CD} 8+\mathrm{T}$ cells which induces proliferation of $\mathrm{T}$ cells and IL-2 (Turnlund et al., 2004). In the context of COVID-19, selenium is an inhibitor of NF-kB which is an important pathway for the progression of coronavirus in the host body. This decreases the effect on endothelial cells and prevents the aggregation of blood cells. Studies also show that supplementation of selenium has proven effective against COVID-19. Selenium when used along with saponins of ginseng stem enhances the immune responses (Ma et al., 2019). Selenium protects the body by radical scavenging, protection against oxidative stress and also by maintaining the antibodies levels.

\subsection{Vitamins}

Vitamins are a group of biocompounds that is highly essential for maintaining a hale immune system. Most of these vitamins cannot be produced by the body itself, hence must be supplemented through food (Thirumdas et al., 2021).

\subsubsection{Vitamin A}

Vitamin A is a fat soluble vitamin that exist in many active forms like retinol, retinal and retinoic acid. $\beta$-carotene, a precursor of vitamin $\mathrm{A}$ acts as antioxidants. Retinoic acid is the most active form which is responsible for immunity through anti-inflammatory actions and also the production of antibodies like IgA (Mullin, 2011). Retinol proliferates the immune cells such as lymphocytes and T-cells at the site of infection. Vitamin A enhances the production of interleukins that rejuvenate pulmonary functions (Yang et al., 2015). Deficiency of vitamin A decreases the immune responses and also increases the oxidative damage and inflammation. Reduction in the retinoic acid inhibits the type 1 interferon pathway that disrupts the normal immune functioning. This is a pattern seen in COVID-19. Supplementing vitamin A increases the activity of B and T cells. In children, supplementation of vitamin shows improved antibody response after administering vaccines (Huang et al., 2018).

\subsubsection{Vitamin C}

Vitamin C is a water soluble compound that supports normal growth and development of the body. It acts as a good enzymatic co-factor in collagen production and hormone synthesis (Kim et al., 2013). Vitamin $\mathrm{C}$ is the most effective antioxidant that scavenges freeradicals and also has immunestimulant impact on phagocytic conditions (Fatima et al., 2020). Studies suggest that vitamin C supplementation increased protection against viral and bacterial infections. $12 \mathrm{~g} /$ day of ascorbic acid enhanced the immunity of patients with respiratory tract infection. Similarly, $15 \mathrm{~g} / \mathrm{day}$ of ascorbic acid reduced the mortality rate of COVID-19 (Carr, 2020). Vitamin $C$ increased the production of interferon $\alpha / \beta$, a vital antiviral factor that boosts immunity. It also increases the immune responses against common cold and flu (Kim et al., 2011). Vitamin C improves the innate and adaptive immunity. It overlooks various cellular functions, thereby improving the immune responses. The epithelial barrier against virus and skin scavenging ability is done by ascorbic acid (Alagawany et al., 2021). It collects and complies neutrophils that perform chemotaxis phagocytosis that kills the microbes. Vitamin $\mathrm{C}$ is also required for neutrophil clearance and apoptosis that inhibits tissue damage and necrosis (Carr and Maggini, 2017). Vitamin C accrue 100 times more in leukocytes than in plasma. During the onsite of an infection, this vitamin $\mathrm{C}$ is utilised faster from leukocytes than from plasma. During the COVID-19 infection, the release of pro-inflammatory cytokines increase along with IL-1 $\beta$ and TNF- $\alpha$ which further stimulates the production of IL-6 and IL-8. Introduction of vitamin $\mathrm{C}$ counteracts this by production of antiinflammatory cytokines like IL-10 which works against IL-6 and controls inflammation against the virus attack (Shakoor et al., 2021).

\subsubsection{Vitamin D}

Vitamin D is a fat soluble vitamin that has two groups D2 and D3. D3 is the group that is involved in the immune system functioning (Fatima et al., 2020). It is responsible for both innate and adaptive immunity and also ACP (antigen-presenting cells) (Aranow, 2011). Vitamin D plays a vital role in the mechanisms of immunemodulatory functions. 1,25-dihydroxy cholecalciferol (1,25 (OH)2D), a vitamin $\mathrm{D}$ metabolite is important in expressing immune responses by activating macrophages and other cell differentiation and proliferation 
(Fatima et al., 2020). This metabolite also advocate chemotaxis and phagocytosis of macrophages. Discovery of vitamin D receptor (VDR) increased the scope of vitamin D beyond its calcium homeostasis and involvement in the mineral and bone health (Wu et al., 2019). VDR along with vitamin D activating enzymes are elevated by $\mathrm{T}$ cells and $\mathrm{B}$ cells activation. Vitamin $\mathrm{D}$ also induces T-cell proliferation; where Th0 is differentiated into Th1, Th2, Th17, etc., that in turn produces cytokines; stimulating innate immune responses against pathogens. Th1 and Th17 are responsible for intracellular pathogenic immunity; while Th2 is responsible for extracellular immunity through humoral immunity. Dendritic cells which are responsible for adaptive immunity is also affected by vitamin D. Vitamin D provides protection against various diseases like hepatitis C, HIV, respiratory infections, inflammatory bowel disorder, multiple sclerosis, rheumatoid arthritis, type 1 diabetes, immune disorders, etc. (Colotta et al., 2017). Clinical trials by Jolliffe et al. (2013) reported the connection between vitamin D deficiency and the risk of upper respiratory tract infections. Similarly, another RCT reported that vitamin D supplementation with very high dosage like 1,00,000 IU/month decreased the respiratory tract infections in aged patients. Vitamin D induces the production of cathelicidin and defensins, antimicrobial peptides that have the potential of an antiviral agent (Shakoor et al., 2021). They show chemotactic activity against viral replication (Klotman and Chang, 2006). Vitamin D supplements along with antiviral drugs has been proven to be effective against HIV, hepatitis, etc. Daily intake of $250 \mu \mathrm{g}$ of vitamin D shows beneficial effects against common cold, respiratory infections by enhancing the physical barrier and boosting the immunity (Grant et al., 2020). COVID-19 is more prevalent among elderly age groups. This can be attributed to the fact of less exposure to sunlight and hence lesser production of 7-DHC (7-dehydrocholesterol) in the skin (Shakoor et al., 2021).

\subsubsection{Vitamin E}

Vitamin $\mathrm{E}$ is another fat soluble vitamin important in regulating immune functions. It is also known as tocopherols $(\alpha, \beta)$ or tocotrienols. It activates cellular and humoral immunity. Vitamin $\mathrm{E}$ increases the Tlymphocyte proliferation and T-cells through cell division. It also acts as antioxidant by scavenging free-radicals. Vitamin E possess chromanol ring in its molecular structure that has the ability to abort PUFA oxidation (Lee and Han, 2018). Vitamin E acts as a chainbreaker of PUFA that absorbs lipid peroxyl radicals which prevents oxidation reactions. Trolox (6-hydroxy-2,5,7,8-tetramethylchroman 2-carboxylic acid), an analogue of vitamin $\mathrm{E}$ has also shown to reduce the oxidative stress. Vitamin E has more radical scavenging capacity than vitamin $\mathrm{C}$ (Boulebd, 2020). Vitamin $\mathrm{E}$ enhances the T-cell production and also supresses the T-cell reducing factors like $\mathrm{PGE}_{2}$. Vitamin E supplementation on mice was conducted in many studies. BouGhanem et al. (2015) suggested that $500 \mathrm{mg} / \mathrm{kg}$ of vitamin $\mathrm{E}$ in the diet decreased viral titers affected by influenza and also decreased pulmonary bacterial infection and lung inflammation due to Streptococcus pneumoniae. Han et al. (2000) said that this was due to enhanced Th1 responses through IFN- $\gamma$ and IL-2. Human studies on vitamin E supplementation by Meydani et al. (1990) showed that adults who were administered with $200 \mathrm{mg}$ /day for 365 days were less susceptible to respiratory infections when compared to the counterparts who were administered with placebo. The mechanism of vitamin $\mathrm{E}$ in immune system was studied by Wu et al. (2016). Vitamin E influences the T-cell division and membrane integrity that acts against respiratory disorders. This produces IL-2 in excess and enhances the immune responses. It also maintains the Th1/Th2 balance. Also, vitamin E possess antiviral capabilities against hepatitis B and other virus (Reboul, 2017). The following studies suggest negative impact of excess vitamin $\mathrm{E}$ on human health. Hemilä and Kaprio (2008) reported vitamin E supplementation increased risk of pneumonia among adult smokers. A similar result was observed among adult patients of respiratory infections. They were supplemented with $200 \mathrm{IU} /$ day of vitamin E. No prominent changes were observed due to the intake of vitamin E (Meydani $e t$ al., 2004). A study called Alpha-Tocopherol Beta- Carotene Cancer Prevention (ATBC) showed positive, neutral and negative effects of vitamin $\mathrm{E}$ supplementation on pneumonia and common cold. The difference in the results were attributed to smoking history, residence, age and many other factors (Hemila and Kaprio, 2011). These disparities should be cleared with consistently characterised population for research.

\section{Health outcomes of nuts}

Nuts are usually included more in Mediterranean diets and cuisines. Recently, the health outcomes of nuts are vastly read and experimented and are being recommended as an important inclusion in regular diets or as a supplement for nutrient deficiency. These nuts are usually known for its lipid content, especially MUFA (Monounsaturated Fatty Acid) and PUFA (Polyunsaturated Fatty Acid). Other health promoting macro and micronutrients present in nuts are fibres, proteins, vitamins $(\mathrm{E}, \mathrm{B})$, and minerals $(\mathrm{Mg}, \mathrm{Cu}, \mathrm{Ca}$, $\mathrm{P}, \mathrm{Zn}, \mathrm{Se}$ ) and also bioactive compounds (Souza et al., 2015). Tree nuts like cashew nuts, almonds, Brazil nuts, walnuts, pistachio nut and legume seed like peanuts are examined and reviewed here. Almonds and cashews have high fraction of MUFA/SFA's while Brazil nuts have lower fractions of the same. Walnuts consist of elevated levels of PUFA's (linolenic acid). Among tree nuts, almond possess highest fibre content (12.5 g/100 g of nuts), while in legume seeds, peanuts are a rich source of both fibre and proteins. The bioactives rich in these nuts are $\alpha$-tocopherol in almonds, phenolics in walnuts, phytosterols in peanuts, selenium in Brazil nuts, etc. (Souza et al., 2017).

These nuts have many favourable consequences on diseases like CVD (Cardiovascular disease), diabetes, obesity, hyperlipidaemia, metabolic disorders, cancers and improve the insulin resistance, lipid profile, and inflammation status and reduces the oxidative stress. Consumption of $10 \mathrm{~g}$ of almonds everyday increased the HDL, while consumption of $60 \mathrm{~g}$ of almonds every day decreased the LDL concentrations (Li et al., 2011). Similarly, including $75 \mathrm{~g}$ of walnuts regularly in the diet decreases the risk of CVD and improves the endothelial functions (Ma et al., 2010). $40 \mathrm{~g}$ of pistachios reduced the glucose concentration by improving glucose metabolism and also reduced LDL and increased HDL concentrations, thereby improving the lipid profile for better cardiovascular function. Approximately, $50 \mathrm{~g}$ of peanuts provides a feeling of satiety and maintains the glucose level. It also enhances the fat oxidation rate, thereby keeping a check on weight gain (Alves et al., 2014). In the aspect of immune responses, antioxidation and anti-inflammatory status of a nut is the most vital factor. Dietary factors such as omega-3 fatty acids, arginine, fibre, vitamin E, magnesium, zinc and selenium are the major determinants in anti-inflammatory mechanisms. A good microbiota is also essential to maintain a healthy immune system. Skins of almonds are rich source of prebiotics. They have polymerised polyphenols, ellagitannins and fibres that are non-bioaccessible that 
renders it unreactive into the colon. This further enhance the concentration of good bacteria (Bifidobacterium spp. and Lactobacillus spp.) in the gut and increases the immunity. Similarly, pistachios and walnuts also possess the prebiotic nature in them (Gervasi et al., 2021).
Most of the nuts have an allergic potential. Consumption of certain nuts elevates serum levels of immunoglobulin and makes the body sensitive to it. This can be reduced through processing steps like roasting that neutralises the allergic reactions and also improves the health-promoting attributes (Downs et al., 2016).

Table 1: Nuts and their related health outcomes

\begin{tabular}{|c|c|c|c|c|}
\hline Sl. No & Nut & Scientific name & Active ingredients & Health benefits \\
\hline 1 & Almond & Prunus dulcis & $\begin{array}{l}\text { Unsaturated fatty acids, vitamin } \mathrm{E} \text {, } \\
\text { vitamin } \mathrm{B}, \mathrm{Mg}, \mathrm{P}, \mathrm{K}\end{array}$ & $\begin{array}{l}\text { Controls LDL, antioxidant, improves } \\
\text { gut microbiota. }\end{array}$ \\
\hline 2 & Peanut & Arachis hypogaea & Arginine, soluble fibres, vitamin B & $\begin{array}{l}\text { Cardiovascular protection, improves } \\
\text { lipid profile }\end{array}$ \\
\hline 3 & Cashew nut & Anacardium occidentale & MUFA, $\mathrm{Zn}, \mathrm{Cu}, \mathrm{Ca}, \mathrm{Mg}$ & Hypertension, cancer, anti-inflammatory \\
\hline 4 & Pistachio & Pistacia vera & Vit $\mathrm{B} 6, \mathrm{Cu}, \mathrm{Mn}$, carotenoid & Diabetes, Obesity, CVD \\
\hline 5 & Walnut & Juglans regia & $\begin{array}{l}\text { Omega-3 fatty acids, vitamin } \mathrm{B} 6 \text {, } \\
\mathrm{Cu}, \mathrm{Mg}, \mathrm{Zn}, \mathrm{Ca}\end{array}$ & Obesity, CHD, CVD, metabolic syndrome \\
\hline 6 & Chestnut & Castanea dentate & Starch, P, Ca, Mg, GABA & $\begin{array}{l}\text { Brain functions, digestive disorders, } \\
\text { antioxidant, anti-inflammatory, } \\
\text { anti-carcinogenic properties }\end{array}$ \\
\hline 7 & Brazil nut & Bertholletia excels & $\mathrm{Se}, \mathrm{Zn}, \mathrm{Cu}$, omega-3 & $\begin{array}{l}\text { Cardioprotective, immunomodulatory } \\
\text { function }\end{array}$ \\
\hline
\end{tabular}

Source: USDA

Table 2: The effect of nut consumption on cardiovascular risk factors summary of scientific evidence

\begin{tabular}{|c|c|c|c|}
\hline S.No & Variables & Effect & Level of evidence \\
\hline \multirow[b]{2}{*}{1.} & Epidemiologic studies & \multirow[b]{2}{*}{ Decrease } & \multirow[b]{2}{*}{++} \\
\hline & Coronary heart disease & & \\
\hline 2. & Sudden cardiac death & Decrease & + \\
\hline 3. & Ischemic stroke & No change & + \\
\hline 4. & Heart failure & No change & + \\
\hline 5 . & Hypertension & Decrease & $+/-$ \\
\hline 6. & Diabetes & No change/decrease & $+/-$ \\
\hline 7. & Cancer & No change/decrease & $+/-$ \\
\hline 8. & Gallstone disease & Decrease & + \\
\hline 9. & Complications of diverticular disease & Decrease & + \\
\hline 10 . & Inflammatory markers & Decrease & + \\
\hline 11. & Body weight & No change/decrease & ++ \\
\hline \multirow[b]{2}{*}{1 . } & Clinical studies & \multirow[b]{2}{*}{ Decrease } & \multirow[b]{2}{*}{++} \\
\hline & Blood cholesterol & & \\
\hline 2. & Insulin sensitivity & No change/decrease & $+/-$ \\
\hline 3. & Blood pressure & Decrease & + \\
\hline 4. & Oxidation & No change/decrease & $+/-$ \\
\hline 5. & Inflammation & No change/decrease & $+/-$ \\
\hline 6. & Vascular reactivity & Increase & + \\
\hline 7. & Body weight & No change & ++ \\
\hline 8. & Visceral adiposity & Decrease & + \\
\hline
\end{tabular}

+/- equivocal evidence; + limited evidence from few studies; ++ consisting evidence in several studies (Ros, 2010). 


\section{Immunomodulatory functions of nuts}

\subsection{Almond: Prunus dulcis (Mill.) D.A.W.B.B}

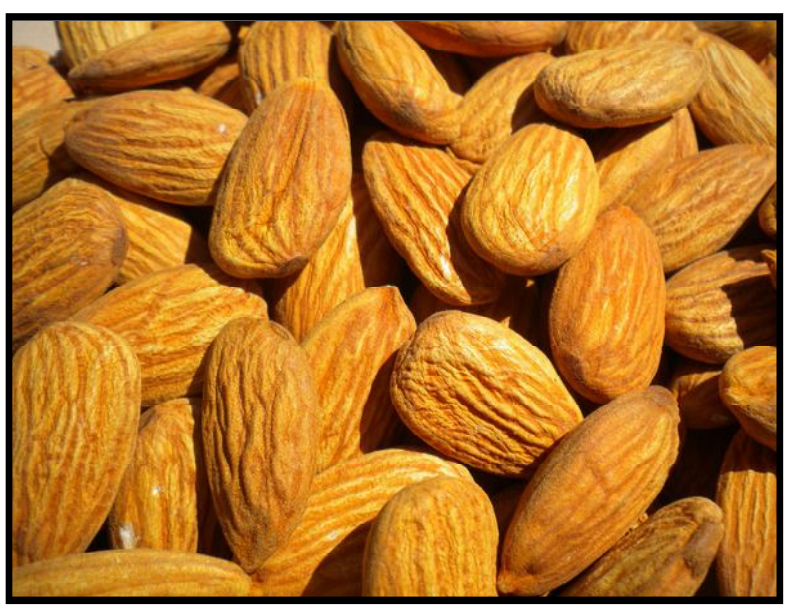

Almonds are classified as dry fruits. They are small sized nuts but loaded with nutrients. Almonds are filled with vitamins (E, A, B) and minerals (Mn, Ca, Mg, P, K). They are also a good source of proteins, fat and fibres (Chen et al., 2006). Catechin, epicatechin, kaempferol, etc., are some flavanoids that regulate the inflammatory process in the body. Flavanones (naringenin) and anthocyanins (cyanidin and delphinidin) along with phenolic acids (caffeic acid, ferulic acid, vanillic acid, p-coumaric acid) possess radical scavenging properties. These nutrients and fibres produce antioxidant and immunemodulatory activities (Burns et al., 2016). The almond skin is rich in fibres that acts as substrate for good microbiota. Studies show an increase in the count of Bifidobacterium and Lactobacillus sp. when $10 \mathrm{~g} / \mathrm{d}$ of almond skin was consumed for a period of 6 weeks (Liu et al., 2014). Lactobacillus work in good digestion, helps lactose intolerant patients by reducing diarrhoea and constipation. It also prevents other pathogenic infections including IBS (Irritable Bowel Syndrome). Bifidobacterium enhances the production of vitamin B and stimulates the functioning of immune system. It also decreases the blood cholesterol and ammonia levels. Both these bacteria produce the compound $\beta$-galactosidases that maintains the gut health (Brigidi et al., 2001). Apart from maintaining good microbiota, consumption of almonds also decreases the risk of harmful microbes like $C$. perfringens that cause gastrointestinal disorders (Liu et al., 2014). Other similar studies suggest, almonds reduced the production of inflammatory cytokines. Prebiotics and probiotics have the potential to improve the immune system. Parkar et al. (2008) studied that the abundant polyphenols present in the almonds also ensures a healthy gut, and thereby a good immune system.

Almonds also advocate heart health by inversely affecting the cardio vascular disorders. The phytosterols and fibres in almonds promote hypocholesterolemic effects; while the fat content in almonds promote vascular health. Copper and $\alpha$-tocopherol looks after the antioxidant properties (Chen et al., 2006). He also reported that almond consumption of $100 \mathrm{~g} /$ day decreased total cholesterol and low-density lipoprotein by $9 \%$ and $12 \%$, respectively. Fraser et al. (2002) studied the effect of almonds on weight gain/loss. Inclusion of $56 \mathrm{~g} /$ day for 6 months resulted in non-significant mean weight gain (400 grams). No difference in waist/hip ratio was observed. Almonds have satiety property that makes the person consume lesser quantities of other foods. Also, the almond fats are not completely absorbable by human cell; thus increase in weight cannot be attributed due to almonds. Another study by Wien et al. (2003) introduced almonds in their low-calorific diet for obese patients. 84 $\mathrm{g} /$ day of almond was included in their diet. The results showed decrease in weight, BMI, waist/hip ratio and fat content. This study also showed increase in insulin concentration. Almonds have low glycaemic index. Vitamin $\mathrm{E}$ in the form of $\alpha$-tocopherol is a very important component in almonds; which is also an important component that possess variety of health benefits. It has high antioxidant capabilities. It also maintains the lipid concentrations which helps maintains cholesterol levels (Jambazian et al., 2005). Studies show that consumptions of nuts also protects cancer.

Consumption of almonds by people who put their body to extreme physical activities is recommended. Physical exercise tends to produce more reactive oxygen species (ROS). This puts extra pressure on the antioxidant defense system which affects the normal functioning of immune system (Yi et al., 2014). This can be balanced by almonds since it has unsaturated fatty acids and large quantities of antioxidants that boosts the antioxidant defense system. Also, the presence of quercetin and arginine in almonds helps maintain the mitochondrial production that compensates for the extra workouts by producing oxygen in excess (Campbell et al., 2004). It also regulated the CHO and glycogen pathways that maintains the energy levels of the athletes. Overall health benefits of almonds include protections against CVD, diabetes, obesity, cholesterol, etc., due to its cardioprotective properties and hypolipidemic effects.

Table 3: Nutritional composition of almond

\begin{tabular}{|c|l|c|}
\hline S.No & Nutrient (Unit) & Per 100 g \\
\hline 1 & Energy (Kcal) & 579 \\
2 & Carbohydrate (g) & 21.55 \\
3 & Protein (g) & 21.26 \\
4 & Fat (g) & 49.93 \\
5 & Dietary fibre (g) & 11.80 \\
6 & Vitamin E ( $\alpha-$ tocopherol) $(\mathrm{mg})$ & 25.87 \\
7 & Vitamin A (IU) & 5.00 \\
8 & Niacin (mg) & 3.93 \\
9 & Riboflavin (mg) & 0.81 \\
10 & Manganese (mg) & 2.54 \\
11 & Calcium (mg) & 248 \\
12 & Magnesium (mg) & 275 \\
13 & Phosphorus (mg) & 474 \\
14 & Potassium (mg) & 728 \\
\hline
\end{tabular}

Source: USDA

Almonds are considered as dry fruits that are consumed during cold to prevent any infections. The antioxidants present in almonds scavenges the free radicals and prevents any kinds of infections with its anti-inflammatory and antihepatotoxic properties (De, 2020). The vitamins and minerals found in almonds strengthens the bone 
and muscle functioning. Antiviral activities of the almond skin was observed due to the presence of polyphenols and fibre. These polyphenols are bioaccessible for digestion in the gastrointestinal tract. These aid in the release of cytokines that act against virus. Activation of immune cells occur with the components in the almond skins. Interleukins, interferons, etc., are proliferated due to the presence of nutrients in almonds. The almond skin is rich in fibre that influence the inflammation of protein kinase $\mathrm{C}(\mathrm{PKC})$ and nuclear factor kappa B (NK-kappa B). Along with antiviral properties and anti-inflammatory properties, they also possess immunomodulatory functions (Arena et al., 2010). Due to its protective nature against so many disorders and the presence of antiviral properties and other health benefits, almond can act as a prospective immune booster food for COVID-19 or any other ailments.

\subsection{Peanut: Arachis hypogaea $\mathrm{L}$.}

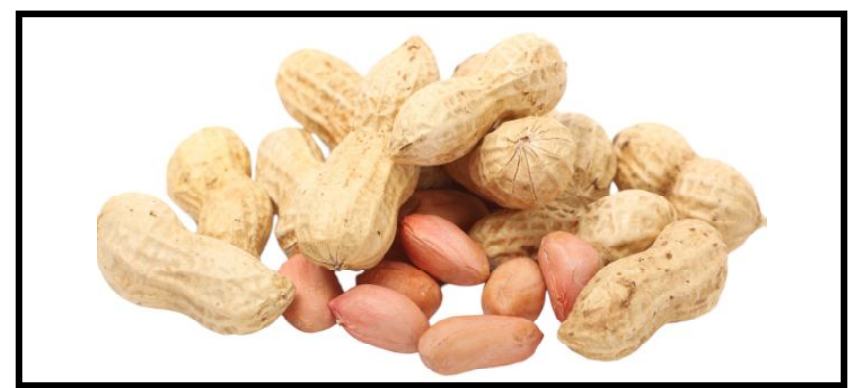

Peanuts are also known as groundnut, which is also seen as an edible portion of the legume family (Fabaceae). China is the largest producer of peanuts with $45 \%$ of overall production while India is in the second place with $16 \%$ share (USDA, 2015). They are used to extract oil in large quantities. They are also used for the manufacturing of peanut butter in large scale and also other eatables involving peanuts. Peanuts are consumed to combat malnutrition in under-developed countries as they are rich source of protein, fat and fibre. The most popularly cultivated peanut varieties are Spanish (in candy, salted peanuts and peanut butter), Runner (in peanut butter), Virginia and Valencia. The latter two varieties are preferred for its large size and shells, oil content, flavour, etc. (Arya et al., 2016).

The wide ranged nutritional composition of peanuts confer wide aspect of health benefits. Protein, fat and fibre content contributes to its major nutrients. The proximate composition of peanuts were estimated as $20.7 \%-25.3 \%$ of protein, $31 \%-46 \%$ of crude fat, $1.2 \%$ $2.3 \%$ of ash, $1.4 \%-3.9 \%$ of crude fibre, $21 \%-37 \%$ of carbohydrate and $4.9 \%-6.8 \%$ of moisture (Alhasaan et al., 2017). Proteins are usually found more in animal products. For vegetarians and vegans, peanuts are the perfect source of protein. This is estimated through its amino acid contents and its digestibility. The amino acid composition varies from different varieties of peanuts. But, an average peanut contains all 20 essential amino acids. The highest quantity of amino acid present is arginine; while the least quantity of amino acid present is sulphur-amino acids (methionine and cysteine) (King et al., 2008). This aminoacid profile makes it a suitable nut for protein fortification. The digestibility quotient for peanuts is $81 \%$ according to PDCAAS (Protein Digestibility Corrected Amino Acid Score). For raw peanuts, the digestibility score is $92.65 \%$. These score make peanut protein's more bioavailable than soybean who's PDDCAAS is $72 \%$ even though, it possess more protein content. These PDCAAS scores are very similar to eggs and other meat sources
(FAO, 2002). Nuts in general have higher lipid content. Peanuts are rich in unsaturated fatty acids, especially MUFA, monounsaturated fatty acids. The health benefits of these unsaturated fatty acids are providing protective actions against CVD, atherosclerosis, etc. They advocate artery-clearing and maintains good blood flow. RCT studies by Alves et al. (2014) showed consumption of high-oleic peanut along with calorie-deficient diet led to fat loss along with insulin secretion. Study by Bonku and Yu (2020) on the effects of MUFA and PUFA on body health reported that they are beneficial against cancer, cognitive reduction and obesity, CVD. Also, HDL was maintained to provide the benefits of good cholesterol. Peanuts are a good source for healthy calories (Arya et al., 2016). The dietary fibre present in peanuts helps in reducing the risks of osteoarthritis, heart diseases, and metabolic disorders like diabetes, cancer, gastrointestinal disorders and other immune disorders. It also lowers the cholesterol levels and has low glycemic index. The soluble fibres react in the gut with the good microbiota and confer health benefits. The insoluble fibres have the ability to interact with carcinogens and other toxic substances, which later can be eliminated through faeces (Wong et al., 2006). 100 grams of peanuts provide $75 \%$ RDA of niacin, $60 \%$ RDA of folate, $53 \%$ RDA of thiamine, $10 \%$ RDA of riboflavin, $35 \%$ RDA of pantothenic acid, $27 \%$ RDA of pyridoxine, 55.5\% RDA of vitamin $\mathrm{E}$. It is a great source of vitamins $\mathrm{B}$ and $\mathrm{E}$ which are important in boosting immunity.

Thiamine is needed for metabolism of energy and nerve functioning. Riboflavin is needed in metabolism of other components like fats, carbohydrates and proteins. This vitamin is also involved in ATP synthesis. Niacin is vital for good digestive and nervous system functioning. Folates, pantothenic acid and choline are collectively required for normal functioning of the body (Bonku and Yu, 2020). Vitamin $\mathrm{E}$ acts as antioxidant and maintains the functioning of cell membranes. Vitamin $\mathrm{E}$ reduces the risk of coronary heart diseases, cancer and other diseases. Vitamins B and E are sensitive to heat. Thus, consumption of raw peanuts is highly beneficial rather than roasted and other processed peanuts (Chukwumah et al., 2007). The mineral content of peanuts are also huge. 100 grams of peanuts contain $127 \%$ copper, $84 \%$ manganese, $57 \%$ iron, $54 \%$ phosphorus, $42 \%$ magnesium of RDA levels. They are also rich in antioxidant minerals like selenium, manganese and cooper. These minerals aid in decreasing the inflammation reactions due to infections and also protect the body from pathogenic attacks (Song et al., 2005).

Arginine is an amino acid present in excess in peanuts. It is an important component in the functioning of immune system. It enhances the production of T-cells and activates the immune system. Studies have proven that arginine can be used in treatment of disorders related to depressed immune system like HIVS, cancer, etc. (Arya et al., 2016). Resveratrol is stilbenes phenolic compounds that are produced when affected by microbes or even due to stress or injury (Jeandet et al., 2012). This antioxidant rich peanut has the potential to fight against cancer, heart diseases, autoimmune disorders like Alzheimer's and even inflammations caused by infections (Gagliano et al., 2010). An array of phytosterols are present in peanut that offer protection against inflammatory disorders. These phytosterols decrease the blood cholesterol by interrupting its synthesis pathway and also by maximizing its output. Lopes et al. (2011) reported that the presence of phenolics acids and flavanoids in the peanuts increase their antioxidant concentration. Some research also report that when peanuts are consumed with their skin doubles the antioxidant levels. 
Similarly, roasting and boiling of peanuts improves the antioxidant concentration. These antioxidants neutralize the harmful free-radical movement, thereby minimizing the damage made by oxidation reactions. This mechanism prevents the incoming of many metabolic and immune disorders (Ros, 2010).

Table 4: Nutritional composition of peanut

\begin{tabular}{|c|l|c|}
\hline S.No & Nutrient (Unit) & Per 100 g \\
\hline 1 & Energy (Kcal) & 567 \\
2 & Carbohydrates (g) & 16.13 \\
3 & Protein (g) & 25.80 \\
4 & Fat (g) & 49.24 \\
5 & Dietary fibre (g) & 8.5 \\
6 & Vitamin E (mg) & 8.33 \\
7 & Thiamine (mg) & 0.640 \\
8 & Riboflavin (mg) & 0.135 \\
9 & Niacin (mg) & 12.066 \\
10 & Manganese (mg) & 1.934 \\
11 & Copper (mg) & 1.144 \\
12 & Zinc (mg) & 3.27 \\
13 & Phosphorus (mg) & 76 \\
14 & Magnesium (mg) & 168 \\
\hline
\end{tabular}

Source: USDA

\subsection{Cashew nut: Anacardium occidentale L.}

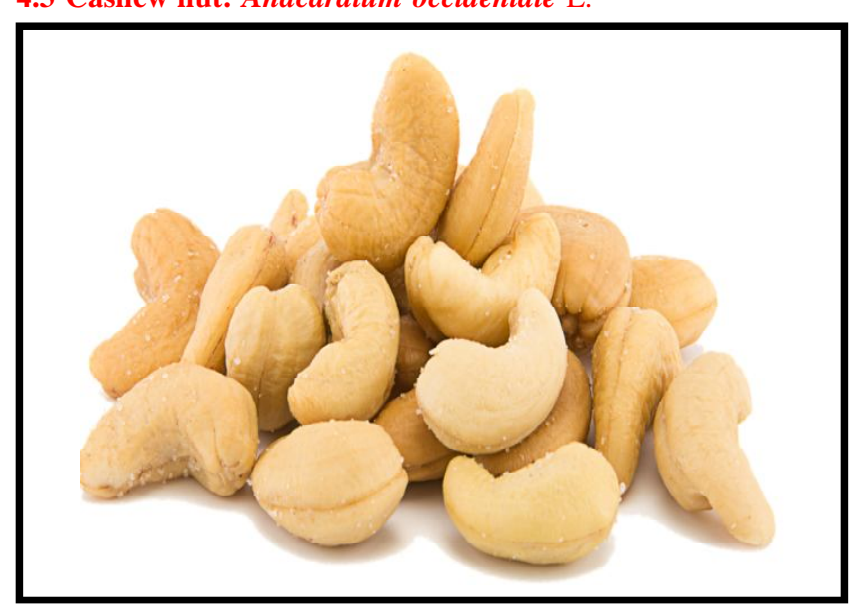

Cashews belong to Anacardiaceae family. Cashew nuts originated from Brazil and are one of the top commercial crops in India. It is also called as "Wonder nut" as it is the only nut found outside the fruits' pulp. The fruit, bark, leaves and shell of this plant has many benefits. Cashews are a very tasty nut that can be consumed raw and are used in many cuisines. Apart from savoury purpose, cashew nuts provide enormous health benefits. Cashew kernels possess $25 \%$ of carbohydrates, $46 \%$ of fats and $21 \%$ of proteins. Apart from these basic nutrients, cashews are also rich in a wide range of vitamins, minerals and other plant phenolics (Vyavahare et al., 2020).

The fats in cashew nuts are mostly unsaturated, both MUFA and PUFA ( $60 \%$ and $20 \%$ of total fat) which confer health benefits. They prevent CVD and other metabolic disorders like obesity, diabetes, etc. The MUFA related oleic acid is rich in cashews that work as cardioprotective agent, as unsaturated fats are good for heart. These unsaturated fat decrease the triglyceride content in the blood due to thermogenic effect, and thereby reduces the risk of heart blockage. Also, the good cholesterol HDL is more in cashews than the LDL, making it a good source of fat. Studies show copper deficiency increases the risk of hypercholesterolemia (Bes-Rastrollo et al., 2009). It was suggested that consumption of cashew nuts reduced the risk of CVD. These nuts due to the presence of MUFA are associated with glucose metabolism which enhances the insulin pathway along with AMPK activation and GLUT4 translocation. The anacardic acid along with polyphenols and fibres in cashews also enhance the insulin pathway, improving its antidiabetic activity and lipid profile (Jamshidi et al., 2021). Cashews are also rich in polyphenolics like proanthocyanidins that offer protection against cancer. They also possess high copper content that reduces the effect of toxic cells. Copper has free-radical scavenging capacity that acts in the antioxidant mechanism. Also, it catalyses superoxide dismutase reactions that provide antioxidant defences. Copper also synergistically works like lysyl oxidase enzyme that works in bone and muscle functioning. Collagen structure involves contribution of copper. Copper deficiency also cause anaemia, osteoporosis, cholesterol, etc. (Marquardt et al., 2012). Along copper, calcium and magnesium are important in bone health. Magnesium acts as calcium blockers in nerves. If, there is a magnesium deficiency, calcium tend to enter the nerve cells. Calcium in nerves causes delirious effects causing over contraction. Thus, required amount of both magnesium and calcium is required to maintain blood pressure, soreness, fatigue and general body health. Apart from these minerals, cashews are also rich in potassium, phosphorus and zinc that are required to maintain a healthy working immune system (Ijarotimi et al., 2012). Vitamin E contributes to approximately $6 \mathrm{mg} / 100 \mathrm{~g}$ of cashews, the highest among its counterparts. Vitamins A and B complex were also found in abundance in these nuts. Bioactive compound lignans and aglycones are present in cashews that contribute to antioxidant capacity and its anti-inflammatory properties and also provide protective effect against CVD, hormonal cancers and osteoporosis. Studies by Cordaro et al. (2020) showed that cashew nuts consumption increased analgesic, antioxidant and anti-inflammatory properties. Other studies also highlighted that these nuts reduced the damage caused by malfunctioning of intestinal barrier. This restricts the pathogen and their toxic materials, thereby preventing the inflammation of liver and kidney and its functioning.

In the aspect of boosting immune health, the presence of vitamin B, vitamin $\mathrm{E}$ and zinc boosts the functioning of immune system. Copper especially renews the blood vessels that helps maintain immune health. Pereira et al. (2018) conducted research and established the effects of cashew extracts combined with polyanhydride nanoparticle in the immune responses of mice. It stimulated humoral and cell mediated immune responses. Cytokine production was recorded that also proliferated IL-10, IL-12, and IFN- $\gamma$. This shows its immunomodulatory properties. The cashewnut tree gum exudate (CNTG) have many medical properties. They show anti-inflammatory activities against tumours and other infections caused by pathogens. The lipopolysaccharides in cashews produce destructive effects against microbes and toxic tumours through macrophage proliferation. This is done by stimulating phagocytic activities that in turn increases the cytokine concentration and TNF- $\alpha$ and IFN- $\alpha$ and IFN- $\beta$ and interleukins (Leung et al., 2006). 
Cashews are eaten in its raw form as kernels and also as roasted nuts. Due to its lower oil content, air dry roasting of cashews are preferred. High temperature treatments not only increases its palatability, but also its nutritional values. Total phenolic contents of cashew nuts increased from $20 \%$ to $344 \%$ when processed at different conditions. Flavonoids such as catechin, epicatechin, etc., and phenolic acids like gallic acid, p-coumaric acid, etc., have also risen in concentration due to heat treatment. Tests also show rise in antioxidant activities under such conditions (Chandrasekara and Shahidi, 2011). These processing techniques also reduce the allergenic effect of cashews. Roasting of cashews reduced the reactivity of the allergens (Ana o 3 and Ana o 1 presents in these nuts (Tufail et al., 2019).

Table 5: Nutritional composition of cashew nut

\begin{tabular}{|c|l|c|}
\hline S.No & Nutrient (Unit) & Per 100 g \\
\hline 1 & Energy (Kcal) & 553 \\
2 & Carbohydrate (g) & 30.19 \\
3 & Protein (g) & 18.22 \\
4 & Fat (g) & 43.85 \\
5 & Dietary fibre (g) & 3.3 \\
6 & Vitamin E (mg) & 5.31 \\
7 & Thiamine (mg) & 0.56 \\
8 & Niacin (mg) & 1.062 \\
9 & Riboflavin (mg) & 0.058 \\
10 & Calcium (mg) & 37 \\
11 & Potassium (mg) & 660 \\
12 & Iron (mg) & 6.68 \\
13 & Zinc (mg) & 5.78 \\
14 & Copper (mg) & 2.2 \\
15 & Magnesium (mg) & 593 \\
16 & Phosphorus (mg) & 292 \\
\hline
\end{tabular}

Source: USDA

\subsection{Pistachio nut: Pistacia vera $\mathrm{L}$.}

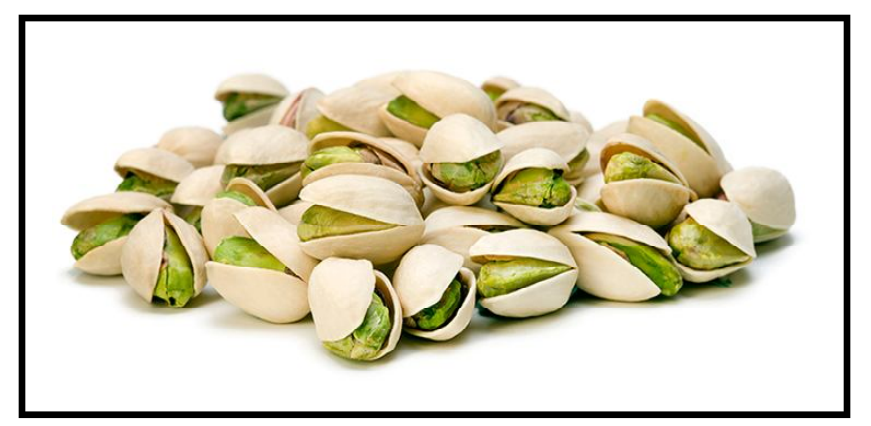

Pistachio nuts originated from Asian Minor countries. They belong to Pistacia family. These nuts have a desert like taste. Pistachio trees grow up to $12 \mathrm{~m}$. Their leaves are oblong-ovoid shaped and dark green in colour. These trees are dioecious. Fruiting of these trees need up to five years; while it takes ten years for the crop to become economically viable. The whole pistachio nut is enclosed inside a shell called endocarp. The seed inside the shell is called kernel and is covered with thin seed coat. The nut itself varies from light green to greenish yellow as it matures. Pistachio nuts are consumed fresh as raw, dried, roasted, and sometimes salted. They are used in many eatables like pastries, desserts, etc. (Kashaninejad and Tabil, 2011).

Pistachios have high nutritive profile which is rich in carbohydrates, fats, proteins and vitamins and minerals. Pistachios contain $10 \%$ of fibres that give a satiety feeling when consumed. This property helps in treating obesity. Also, pistachios have low glycaemic index that reduces the postprandial glucose; thereby treating diabetes (Terzo et al., 2019). The fat content in pistachio is less about $45.4 \mathrm{~g} / 100 \mathrm{~g}$ of which, $5.6 \mathrm{~g}$ is saturated fatty acids, $13.7 \mathrm{~g}$ is PUFA and $23.8 \mathrm{~g}$ is MUFA. The unsaturated fatty acids like oleic and linoleic acids possess cardioprotective properties. Also, palmitoleic acid in the form of MUFA in pistachios possess anti-inflammatory properties. When these nuts are grown in high temperatures of $25^{\circ} \mathrm{C}$ and above, the presence of saturated fatty acids can be prevented (Satil et al., 2004). Pistachios constitute about $20 \%$ of protein by weight. Arginine (9.15 $\mathrm{g} / 100 \mathrm{~g}$ ) one of the most important amino acid in maintaining homeostasis is found in abundance in these nuts. It is known as a precursor of NO, which has many health benefits like modulating antioxidant activities. It also regulates vasodilation process in treating CVD and neurodegenerative disorders (Venkatachalam and Sathe, 2006). Vitamin B-complex is found in excess as many units exceed the RDA. Similarly, vitamins A, E and K are also present in pistachio that gives protective nature against CVD, T2DM, bone metabolism and other inflammatory disorders. Vitamin B6 promotes a good blood flow and maintains the lymphoid glands (lymph nodes, spleen and thymus). These glands are responsible for proper functioning of immune system by producing the immune cells for defense. Minerals like $\mathrm{P}, \mathrm{K}, \mathrm{Mg}, \mathrm{Mn}, \mathrm{Zn}, \mathrm{Se} \mathrm{Cu}$ and $\mathrm{Ca}$ are present in pistachio nuts. They are responsible for regulating cellular functioning and prevent against CVD and other metabolic disorders and also to maintain the blood pressure. Zinc and selenium in specific is responsible for working of immune system (Huang et al., 2006). Pistachios are also rich in plant phytochemicals. The phenolic compounds of pistachios like flavonoids, anthocyanin, phenolic acids, tannins, etc., shows chemopreventive, cardioprotective and vaso-protective abilities. They also show high antioxidant and anti-inflammatory activities which decreases the risk of cancer and CVD; and reduces the LDL. The harmful effects of lipid oxidation are reduced when these phenolic compounds interact with metal (Bulló, et al., 2015). Pistachios are the only nuts that has significant amount of $\alpha$-and $\beta$-carotene, lutein and zeaxanthin, a form of carotenoid. They show strong antioxidant properties. They exhibit mechanisms to decrease the LDL synthesis and maintain a good lipid profile (Karppi et al., 2010).

Nuts in general are perceived as high fat content foods. But in reality, good cholesterol and good fat helps in reducing the body fat content and body weight. Studies show that when pistachios are consumed at regular intervals, there was a visible reduction in BMI. Thus, these nuts are employed in diets. The high fat, protein content and unsaturated fats give a satiated feeling and also produce thermogenic effects that reduce the risk of obesity. RCT conducted to evaluate the effect of pistachios on weight control. Low calorie diet along with pistachio supplementation was introduced to obese people (Gulati et al., 2014). The result showed significant reduction in the BMI along with waist: hip ratio. Pistachios also increase the insulin sensitivity that reduces the risk of T2DM. Proanthocyanidins in 
pistachio nuts inhibit the inflammatory responses of epithelial cells by curbing the NF-KB mechanisms (Gentile et al., 2015). Adiponectin, an adipocyte-related hormone that possess anti-inflammatory activities have been found to increase in concentration due to pistachio inclusion in the diet. The polyphenols and other phytosterols in pistachios acts as free radical scavenger. Lipid oxidation due to reactive oxygen species are prevented by these nuts. The leaves and the hull of pistachios also possess antioxidant properties, and hence can be used as supplements in pharmaceutical industries (Grace et al., 2016).

Table 6: Nutritional composition of pistachio nut

\begin{tabular}{|c|l|c|}
\hline S.No & Nutrient (Unit) & Per 100 g \\
\hline 1 & Energy (Kcal) & 560 \\
2 & Carbohydrate (g) & 29 \\
3 & Protein (g) & 26.16 \\
4 & Fat (g) & 45.4 \\
5 & Dietary fibre (g) & 10.6 \\
6 & Vitamin C (mg) & 5.6 \\
7 & Vitamin E (mg) & 2.86 \\
8 & Thiamine (mg) & 0.87 \\
9 & Riboflavin (mg) & 0.16 \\
10 & Niacin (mg) & 1.3 \\
11 & Vitamin B6 (mg) & 1.7 \\
12 & Calcium (mg) & 105 \\
13 & Magnesium (mg) & 121 \\
14 & Phosphorus (mg) & 490 \\
15 & Zinc (mg) & 2.2 \\
\hline
\end{tabular}

Source: USDA

\subsection{Walnut: Juglans regia L.}

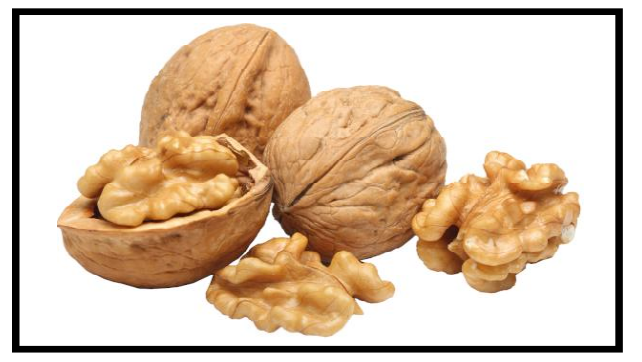

Walnut was originated in Central Asia and Eastern European countries. It belongs to Juglandaceae family. China is the top producer of walnuts while India is the seventh largest producer. It has been in use for many thousands of years. Walnuts are used in daily consumption due to its numerous health benefits. These nuts are brain shaped and also highly associated with brain's wellness. Walnuts possess huge amount of fats, protein, vitamins and minerals. It is also rich in antioxidant sources and other healthy plant polyphenols. These nuts provide protection to various body functions and effects many diseases and disorders like CVD, high cholesterol, cancer, neurological disorders, inflammatory disorders, immune functions, etc. Apart from consumption for its nutritional benefits, walnuts are used for dyeing and manufacturing of wool (Hayes et al., 2016).

The fat in walnuts is around $65 \%$ of its weight. These fat constitute to its energy through the calorie content. The fat in walnuts is mostly mono-unsaturated fatty acids; especially omega 3 and omega 6 fatty acid and arachidonic acid. These omega fats are highly beneficial in cardio health. These improve the lipid profile and reduces the cholesterol content. Many studies established a strong link between the fats present in walnuts and its protective nature for CHD, CVD and metabolic disorders like hyperlipidaemia (Micha and Mozaffarian, 2010). Omega 3 and omega 6 showed relationship between increased proinflammatory responses. Research conducted by Tapsell et al. (2004) produced results that inclusion of walnuts in the diet of T2DM improved the subjects HDL and improved their lipid profiles. This has an impact on the cardio health. Another aspect of the importance of omega fats were studied by many researchers. They deduced a connection between consumption of walnuts and the hormone levels in the serum. Two of the most important such hormones that has anti-inflammatory effects are adiponectin and apolipoprotein. The higher the ratio of omega 3: omega 6 fat, the higher the carcinogenesis occurs (Jiang et al., 2012). Linolenic acid present in walnuts as PUFA destructed the cancerous cells. Also, omege 3 fatty acids are used in the treatment of neurological disorders like Alzheimer's in ageing patients. Experiments on rat show the correlation between walnut consumption and enhanced cognitive abilities (Willis et al., 2009). The presence of tocopherols prevents lipid oxidation.

Fibre and protein content in walnuts attributes to many medical benefits. The amino acid, arginine is a precursor of NO, which acts an effective vasodilator. These nuts also constitute important minerals like copper, phosphorus, manganese, etc., they are vital in maintaining the immune system (Fatima et al., 2018). Walnuts are a rich source of vitamins $\mathrm{E}$ and B complex. Vitamin $\mathrm{E}$ is present in two forms ( $\alpha$ tocopherol and $\gamma$-tocopherol). Walnuts satisfy about $140 \%$ of the RDA of vitamin E. This fat soluble vitamin acts as a strong antioxidant that scavenges free radicals and keeps the body from inflammation or infections. Vitamin B as thiamine, niacin, riboflavin, folate, B6, pantothenic acid is present in walnuts. They also provide antiinflammatory effects. This vitamin specifically controls the blood pressure and checks on heart health and also maintains the functioning of nervous system. Vitamin B is very important to regulate the immune system (Sen and Karadeniz, 2015).

Walnuts possess a complex variety of phytochemicals including tannins, phenolic acids, flavonoids, etc. The extract of walnut consisting of ellagic acid and other polyphenols like tannins has proven to inhibit plasma and LDL lipid oxidation. Studies also show regular consumption of walnuts reduced LDL due to the effects of these polyphenolic compounds along with $\alpha$-tocopherol (Anderson et al., 2001). The phenolic acids (especially ellagic acid) proves to be an inhibitor of cancer cells. These acids also inhibit auto-oxidation of lipids. Stilbenes in walnuts assume the form transresveratrol (trans3,4',-5-trihydroxystilebene). This compound exhibit antimicrobial activity. They also possess anti-inflammatory, antioxidant and antitumour properties (Smoliga et al., 2011). Ellagitannins is the polyphenol structure present in walnut that is hydrolysed with mineral acids from digestion to obtain ellagic acid. This ellagic acid is further metabolised as urolithins A and B which is absorbed in the human body. These ellagic acid also plays a protective role in nicotine- 
induced toxicity in rat models. The blood lymphocytes filled with nicotine increased the oxidation process which destructed the DNA processing (Sudheer et al., 2007). Ellagitannins also show high antiinflammatory properties by inhibiting the inflammatory process. Affecting the inflammatory molecules like NO, IL- $1 \beta$, TNF- $\alpha$, COX2 , etc. Walnuts are known for its immunomodulatory properties. The presence of oligopeptides in walnuts attribute to this bioactivity. This was tested on mice by Mao et al. (2020) to study the effect of walnuts oligopeptides and its immunomodulatory effects. The study proved the phagocytic capabilities of walnuts by increasing the innate and adaptive immunity. The concentrations of NK immune cells, T cells, spleen cells, cytokines, etc., increased exponentially. Blymphocytes were activated producing antibodies. Immunoglobulins are produced during any external pathogenic attack. This shows the effect of walnuts on the immune system of the human body.

Table 7: Nutritional composition of walnut

\begin{tabular}{|c|l|c|}
\hline S.No & Nutrient (Unit) & Per 100 g \\
\hline 1 & Energy (Kcal) & 654 \\
2 & Carbohydrate (g) & 13.71 \\
3 & Protein (g) & 15.23 \\
45 & Fat (g) & 65.21 \\
6 & Dietary fibre (g) & 6.7 \\
7 & Vitamin E (mg) & 0.7 \\
8 & Vitamin K ( $\mathrm{gg})$ & 2.7 \\
9 & Vitamin C (mg) & 1.3 \\
10 & Thiamine (mg) & 0.341 \\
11 & Riboflavin (mg) & 0.15 \\
12 & Niacin (mg) & 1.125 \\
13 & Vitamin B6 (mg) & 0.537 \\
14 & Calcium (mg) & 98 \\
15 & Iron (mg) & 2.91 \\
16 & Magnesium (mg) & 158 \\
17 & Phosphorus (mg) & 346 \\
18 & Potassium (mg) & 441 \\
19 & Zinc (mg) & 3.09 \\
20 & Manganese (mg) & \\
\hline
\end{tabular}

Source: USDA

4.6 Chestnut: Castanea sativa Mill.

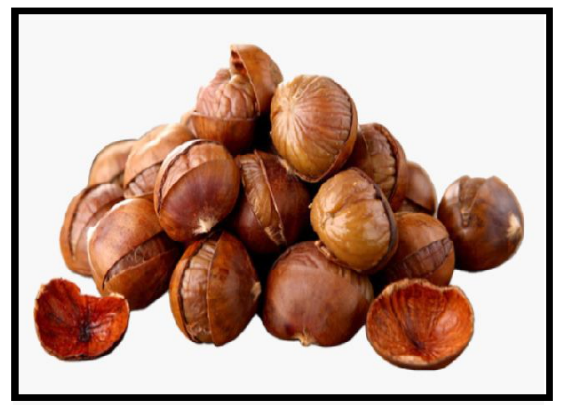

Chestnuts are edible nut varieties that grow in temperate regions in northern hemispheres. They belong to Fagaceae family (Beech family). These nuts have been a staple food in European and Asian countries where cultivation of cereals was difficult. It was also called as 'bread-tree' due to this reason. Italy is the leading producer of chestnut. Due to its health benefits, the consumption of chestnut has doubled in the past few decades. They are rich in carbohydrate, fibre, and vitamin and mineral but low in fat content. Chestnuts are sold as raw nut, roasted, boiled, frozen and also crystallised. They are usually marketed after a few processing steps to improve their organoleptic properties and to make them more palatable; since they possess a bitter taste in its natural form due to the presence of tannins (Wani et al., 2017). These marketed nuts are used in many edible foods like cakes, bread, gluten-free beers, candied nuts, etc. Not just nuts, the whole plant of the chestnut has been proven beneficial. Flowers, nectar, pollens, bark, kernel, etc., all have good antioxidant property, antitumour activity and also protect against metabolic and cardiodisorders. The honey from the chestnuts' flowers is abundant in minerals like calcium, manganese and potassium which enhances it antibacterial properties; hence used for wound dressing. Similarly the flowers possess antimelanogenic property and can be used in food and pharmaceutical industries (Sapkota et al., 2010).

Chestnuts are rich in starch content, accounting for about $50 \%$ of its weight. Its starch content is more than that of potatoes, and hence are consumed for its health benefits. Amylose and amylopectin and the sugar content in the form of sucrose provide the energy source from chestnuts. These sugars also act for its palatability factor. The fibre content of these attribute to the protective nature for metabolic disorders, cardiovascular disorders, lipid profile, etc. In contempt of low fat content, these nuts possess good amount of unsaturated fatty acids like linoleic and linolenic acids that attribute to neuroprotective and cardioprotective properties, along with antitumour activities (Vasconcelos et al., 2010). The protein content in chestnut is ordinary that meets about $9.2 \%$ of RDA in females and $7.6 \%$ in males. Aspartic acid, glutamic acid, arginine, GABA are the prominent amino acids contributing to the medical benefits. GABA is known for its mechanism as neurotransmitter inhibitor which regulates the CNS functioning. This property protect the human body against neurological disorders like Alzheimer's and Parkinson's diseases (Gajcy et al., 2010). The chestnuts are rich in vitamins C and $\mathrm{E}$ which are the most essential vitamins to maintain immune system. They provide good protection against pathogens and also possess anti-inflammatory and antioxidant activities. Vitamin E provides protection against CVD and cancers. Vitamins A and Bcomplex are also seen in a considerable amount in these nuts. Thiamine, riboflavin, folates, pantothenic acid, etc., works to provide good brain and nervous system functioning (Barros et al., 2011). These nuts are also abundant in minerals like $\mathrm{Ca}, \mathrm{K}, \mathrm{P}, \mathrm{Zn}, \mathrm{CU}$, etc., The bioactive compounds like phenolic acids, flavanoids, etc., are present in the whole plant rather than just the nuts. Some important polyphenols that provide health-promoting activities are ellagic acid and gallic acid. These compounds provide antiplasmodic and anticarcinogenic activities (Okuda, 2005).

There are numerous health benefits provided by chestnut consumption. Due to its less fat content, it can be confidently eaten by people who are conscious of weight gain. The essential fatty acids present in chestnuts maintain the serum lipid profile, insulin activity and also immune functions. The extracts of the nuts reduced the cholesterol level and also decreased the lipid oxidation, specifically 
LDL that induces damages in cardiovascular pathways. Fibres in chestnut also participates in the mechanism that control fat in the body. Jesch and Carr (2017) elucidated a pathway to understand this process. The fibres in the nuts are fermented by the microbiota which lag the gastric emptying process and enhances the glucose uptake via glucose transporter type 4 expression. This will lead to less absorption of fat while the excretion of fat is more. Fibres also improve the gut flora (Bifidobacterium and Lactobacillus) that decreases the LDL and cholesterol levels. These dietary fibres also provide therapeutic effects against diabetes and many types of cancer. Cancer protection is associated to the bioactive compounds in the chestnut like omega-3 fatty acids, ellagic acid, gallic acid, vitamin C and vitamin $\mathrm{E}$. These vitamins synergistically act as a strong antioxidant and reduce the risk of CVD and cancer. While vitamin B increases the iron metabolism and improves the hematologic condition (Powers, 2003). Chestnuts possess optimal amount of both macroelements and micro-elements. Calcium deficiency results in osteoporosis, hyperlipidaemia and also increases the blood pressure. Magnesium deficiency results in metabolic disorder, cardiovascular disorders, etc. Potassium is important in CNS functioning. Zinc and copper are very important minerals in regulating the immunomodulatory functions (Martínez-Ballesta et al., 2010). The chestnut honey has innumerable health properties. It is used for treating cold and upper respiratory tract infections. It also possess strong antioxidant and anti-inflammatory activities. Güne et al. (2017) reported that the honey show antimicrobial activities against virus, bacteria and fungi due to its phenolic content. Propolis is a bee product that can be generated form chestnut flowers. This product has shown to improve the host defense mechanisms and provide antimicrobial properties. The propolis flavonoid enhances the cellular and humoral mediated immunity.

Table 8: Nutritional composition of chestnut

\begin{tabular}{|c|l|c|}
\hline S.No & Nutrient (Unit) & Per 100 g \\
\hline 1 & Energy (Kcal) & 196 \\
2 & Carbohydrate (g) & 44.2 \\
3 & Protein (g) & 1.6 \\
4 & Fat (g) & 1.3 \\
5 & Vitamin E (mg) & 1.2 \\
6 & Vitamin C (mg) & 40.2 \\
7 & Thiamine (mg) & 0.23 \\
8 & Riboflavin (mg) & 0.168 \\
9 & Niacin (mg) & 1.1 \\
10 & Vitamin B6 (mg) & 0.4 \\
11 & Calcium (mg) & 27 \\
12 & Iron (mg) & 0.9 \\
13 & Magnesium (mg) & 30 \\
14 & Phosphorus (mg) & 93 \\
15 & Copper (mg) & 0.4 \\
16 & Zinc (mg) & 0.52 \\
17 & Manganese (mg) & 0.3 \\
\hline
\end{tabular}

Source: USDA
4.7 Brazil nut: Bertholletia excelsa Humb. \& BONPL.

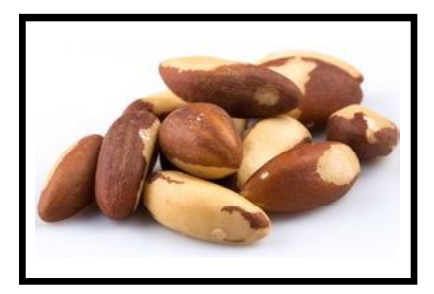

Brazil nuts originated in the South America. They belong to Lecythidaceae family and grows in tropical regions. The Brazil nut trees are evergreen and grow very tall up to $150 \mathrm{ft}$ in height. Its nuts are round in shape about 6 inches in diameter. These Brazil nuts bear fruits that are pear-shaped. These Brazil nut fruits individually consist of 12 to 24 nuts. These nuts are elongated in shape (Yang, 2009). This nut is known for its selenium content. It satisfies about 100 times the RDA of selenium. Selenium is an excellent source of antioxidant and plays a very important role in immunemodulatory functions. This element also reduce the risk of neurodegenerative disorders, cancers, etc. It also regulates thyroid functioning (Meplan and Hesketh, 2014).

The nutritional composition of Brazil nuts is $3.5 \%$ of water, $12.3 \%$ of carbohydrates, $14.3 \%$ of protein and $66.4 \%$ of fats. This high level of fats and protein usually gives a satiety feeling after consumption of this seed. They have low concentration of saturated fats $(15 \%)$ and large quantities of unsaturated fatty acids (MUFA$25 \%$ and PUFA-21\%). These unsaturated fatty acids in Brazil nuts are mainly oleic, linoleic, omega-3 (7\%) and omega- 6 fatty acids (Cardoso et al., 2017). The protein content in these are lower when compared to other nuts. Brazil nuts contain various trace elements that provide many healthy attributes. These elements are used as co-factor in many metabolic pathways in the body. Brazil nuts are rich in magnesium, calcium, zinc and selenium. Other minerals present in these nuts are copper, chromium, iron, etc. Selenium in Brazil nuts are the highest than any other nuts like cashew nuts, walnuts, peanuts, etc. The concentration of Se is dependent on the type of soil. Brazil nuts grown in central parts of Brazil, have more Se concentration than the same type of Brazil nuts grown in western Brazil (Dumont et al., 2006). The bioactive compounds in nuts include phenolic acids, flavanoids, phytosterols, etc. The main activities of these compounds are antioxidant and anti-inflammatory properties. In Brazil nuts, these bioactives are either in esterified or free form. Brazil nuts and almonds possess the highest concentration of polyphenols in comparison to its counterparts (Alasalvar and Bolling, 2015). Brazil nuts consist of considerable amounts of tocopherols, flavanols and sterols. Other important value addition providing compounds found in these nuts are ellagic acid, gallic acid, protocatechuic acid and catechin. These attribute to the nuts' antioxidant capabilities. The brown skin on the kernels contains more quantities of these phenolics than the kernel and other parts. Brazil nuts consist of higher concentration of squalene, which is a strong antioxidant.

The most unique feature of Brazil nut is the immense amount of selenium. Though, it does not primarily act as an antioxidant, it acts as an important antioxidant enzyme. This element along with zinc and copper provides a strong immune system. Functioning of thyroid glands is regulated by Se. This is highly necessary as thyroid and its hormones are one of the first line of defense. Se with vitamin $\mathrm{E}$ acts 
against many cancers and provide anticancerous property. The mechanism behind this is by stopping the cell cycle of the tumour cells and promoting apoptosis (Jiang et al., 2001). Many RCT shows the connection of increased intake of selenium in diet and decrease in the risk of many cancers including prostate cancer, mammary cancer, gastric cancer, colon cancer (Yang, 2009). Consumption of these nuts $(50 \mathrm{~g})$ increased the IL-10 which promotes anti-inflammatory activities while decreased pro-inflammatory interleukins. Antioxidant inducing selenoproteins were increased in the serum due to inclusion of these nuts in the diet. Colpo et al. (2013) conducted studies suggesting that $20 \mathrm{~g}$ of Brazil nuts increased the HDL and decreased the concentration of LDL. Thus, these nuts can be used by obese patients to improve their lipid profile without increasing their cholesterol levels. Insulin levels were regulated during this period. All these evidences show the nuts' protective nature against CVD.

Table 9: Nutritional composition of Brazil nut

\begin{tabular}{|c|l|c|}
\hline S.No & Nutrient (Unit) & Per 100 g \\
\hline 1 & Energy (Kcal) & 656 \\
2 & Carbohydrate (g) & 11.47 \\
3 & Protein (g) & 14.3 \\
4 & Fat (g) & 66.4 \\
5 & Dietary fibre (g) & 7.5 \\
6 & Vitamin E (mg) & 7.87 \\
7 & Vitamin C ( $\mathrm{gg})$ & 0.7 \\
8 & Thiamine (mg) & 0.6 \\
9 & Riboflavin (mg & 0.035 \\
10 & Niacin (mg) & 0.3 \\
11 & Vitamin B6 (mg) & 0.1 \\
12 & Calcium (mg) & 160 \\
13 & Iron (mg) & 2.4 \\
14 & Magnesium (mg) & 376 \\
15 & Phosphorus (mg) & 725 \\
16 & Copper (mg) & 1.7 \\
17 & Zinc (mg) & 4.1 \\
18 & Manganese (mg) & 1.2 \\
19 & Selenium (mcg) & \\
\hline
\end{tabular}

Source: USDA

\section{Conclusion}

Proper nutrition is required to support the immune system to work against pathogenic attacks. Deficiency of these macro and micro nutrients take a toll on the bodys' health. In times of pandemic like COVID-19, intake of highly nutritious balanced diet provides many health-promoting activities. Foods like vegetables, fruits and nuts that boost the immune system should be strictly accommodated in the daily diet to counteract the pathogens. PUFA, omega-3 fats, vitamins E, C, B-complex and minerals like zinc, copper and selenium play a vital role in enhancing the immunomodulatory properties. The anti-inflammatory capability and antioxidant status of the body are very important to provide protection against diseases. Flavanoids, phytosterols, phenolic acids, etc., are bioactive compounds that promote healthy attributes. Nuts are energy dense food with many health effects that are backed up by profuse evidences from clinical trials and epidemiological studies. Inclusion of nuts in diet administer cardio-protective effects and also protects from metabolic disorders, obesity, diabetes, inflammation, etc. Apart from these properties, nuts also enhance the immunity in human body by offering protection from external pathogens. The nuts discussed here are almonds, cashew nuts, peanuts, walnuts, Brazil nuts and chestnuts which contain various beneficial components in abundance and consumption of these nuts in required quantities offer well-being.

\section{Acknowledgements}

This review was carried out as part of the project (TIDE SEED/ TITE/2019/77) financially supported by Department of Science and Technology. Authors wish to acknowledge Department of Science and Technology for their financial support extended for the project and management of Sri Krishna College of Engineering and Technology for the support extended to carry out the project in the campus.

\section{Conflict of interest}

The authors declare no conflicts of interest relevant to this article.

\section{References}

Alagawany, M; Attia, YA; Farag, MR; Elnesr, SS; Nagadi, SA; Shafi, ME; Khafaga, AF; Ohran, H; Alaqil, AA and Abd El-Hack, ME. (2021). The strategy of boosting the immune system under the COVID-19 pandemic. Front. Vet. Sci., 7:570748.

Alasalvar, C. and Bolling, B. W. (2015). Review of nut phytochemicals, fatsoluble bioactives, antioxidant components and health effects. The British Journal of Nutrition, 113(2):S68-S78.

Alhassan, K; Agbenorhevi, J. K; Asibuo, J. Y and Sampson, G. O. (2017). Proximate composition and functional properties of some new groundnut accessions. Journal of Food Security, 5(1):9-12.

Alroy, I; Towers, T. L and Freedman, L. P. (1995). Transcriptional repression of the interleukin-2 gene by vitamin D3: Direct inhibition of NFATp/ AP-1 complex formation by a nuclear hormone receptor. Molecular and Cellular Biology, 15(10):5789-5799.

Alves, R. D; Moreira, A. P; Macedo, V. S; de Cássia Gonçalves Alfenas, R; Bressan, J; Mattes, R and Costa, N. M. (2014). Regular intake of high-oleic peanuts improves fat oxidation and body composition in overweight/obese men pursuing a energy-restricted diet. Obesity (Silver Spring, Md.), 22(6):1422-1429.

Anderson, K. J; Teuber, S. S; Gobeille,A; Cremin, P; Waterhouse, A. L. and Steinberg, F. M. (2001). Walnut polyphenolics inhibit in vitro human plasma and LDL oxidation. The Journal of Nutrition, 131(11):2837-2842.

Aranow C. (2011). Vitamin D and the immune system. Journal of Investigative Medicine : The Official Publication of the American Federation for Clinical Research, 59(6):881-886.

Arena, A; Bisignano, C; Stassi, G; Mandalari, G; Wickham, M. S and Bisignano, G. (2010). Immunomodulatory and antiviral activity of almond skins. Immunology Letters, 132(1-2):18-23.

Arya, S. S; Salve, A. R and Chauhan, S. (2016). Peanuts as functional food: A review. Journal of Food Science and Technology, 53(1):31-41.

Barnett, J. B; Dao, M. C; Hamer, D. H; Kandel, R; Brandeis, G; Wu, D; Dallal, G. E; Jacques, P. F; Schreiber, R; Kong, E and Meydani, S. N. (2016). Effect of zinc supplementation on serum zinc concentration and $\mathrm{T}$ cell 
proliferation in nursing home elderly: A randomized, double-blind, placebo-controlled trial. The American Journal of Clinical Nutrition, 103(3):942-951.

Barros, A. I; Nunes, F. M; Gonçalves, B; Bennett, R. N and Silva, A. P. (2011). Effect of cooking on total vitamin $\mathrm{C}$ contents and antioxidant activity of sweet chestnuts (Castanea sativa Mill.). Food Chemistry, 128(1):165-172.

Bes-Rastrollo, M; Wedick, N. M; Martinez-Gonzalez, M. A; Li,T. Y; Sampson,L and Hu, F. B. (2009). Prospective study of nut consumption, long-term weight change, and obesity risk in women. The American Journal of Clinical Nutrition, 89(6):1913-1919.

Bonku, R and Yu, J. (2020). Health aspects of peanuts as an outcome of its chemical composition. Food Science and Human Wellness, 9:2130 .

BouGhanem, E. N; Clark, S; Du, X; Wu, D; Camilli, A; Leong, J. M and Meydani, S. N. (2015). The $\alpha$-tocopherol form of vitamin $E$ reverses ageassociated susceptibility to streptococcus pneumoniae lung infection by modulating pulmonary neutrophil recruitment. Journal of Immunology (Baltimore, Md.: 1950), 194(3):1090-1099.

Boulebd, H. (2020). Comparative study of the radical scavenging behavior of ascorbic acid, BHT, BHA and Trolox: Experimental and theoretical study. Journal of Molecular Structure, 12(1):127-210.

Brigidi, P; Vitali, B; Swennen, E; Bazzocchi, G and Matteuzzi, D. (2001). Effects of probiotic administration upon the composition and enzymatic activity of human fecal microbiota in patients with irritable bowe syndrome or functional diarrhea. Research in Microbiology, 152(8):735-741.

Bulló, M; Juanola-Falgarona, M; Hernández-Alonso, P and Salas-Salvadó, J. (2015) Nutrition attributes and health effects of pistachio nuts. The British Journal of Nutrition, 113:S79-S93.

Burns, A. M; Zitt, M. A; Rowe, C. C; Langkamp-Henken, B; Mai, V; Nieves, C; Jr; Ukhanova, M; Christman, M. C and Dahl, W. J. (2016). Diet quality improves for parents and children when almonds are incorporated into their daily diet: A randomized, crossover study. Nutrition Research (New York, N.Y.), 36(1):80-89.

Campbell, B.I; La Bounty, P.M. and Roberts, M. (2004). The ergogenic potential of arginine. J. Intl. Soc. Sports Nutr., 1:35.

Cardoso, B. R.; Duarte, G; Reis, B. Z. and Cozzolino, S. (2017). Brazil nuts: Nutritional composition, health benefits and safety aspects. Food Research International (Ottawa, Ont.), 100(2):9-18.

Carr, A. C and Maggini, S. (2017). Vitamin C and immune function. Nutrients, 9(11): 1211 .

Carr, A. C. (2020). A new clinical trial to test high-dose vitamin C in patients with COVID-19. Critical Care, 24(1):1-2.

Chandrasekara, $\mathbf{N}$ and Shahidi, F. (2011). Antioxidative potential of cashew phenolics in food and biological model systems as affected by roasting. Food Chemistry, 129:1388-1396.

Chang, HC; Bayeva, M; Taiwo, B; Palella, FJ Jr; Hope, TJ and Ardehali, H. (2015). Short communication: high cellular iron levels are associated with increased HIV infection and replication. AIDS Res. Hum. Retroviruses, 31(3):305-312.

Chen, C.-Y; Lapsley, K and Blumberg, J. (2006), A nutrition and health perspective on almonds. J. Sci. Food Agric., 86:2245-2250.

Chen, $L$ and Huang, G. (2018). The antiviral activity of polysaccharides and their derivatives. International Journal of Biological Macromolecules, 115:77-82.
Chowdhury, M. A; Hossain, N; Kashem, M. A; Shahid, M. A and Alam, A. (2020). Immune response in COVID-19: A review. Journal of Infection and Public Health, 13(11):1619-1629.

Chukwumah, Y; Walker, L; Vogler, B and Verghese, M. (2007). Changes in the phytochemical composition and profile of raw, boiled, and roasted peanuts. Journal of Agricultural and Food Chemistry, 55(22):92669273.

Colotta, F; Jansson, B and Bonelli, F. (2017). Modulation of inflammatory and immune responses by vitamin D. Journal of Autoimmunity, 85:78-97.

Colpo, E; Vilanova, C. D; Brenner Reetz, L. G; Medeiros Frescura Duarte, M. M; Farias, I. L; Irineu Muller, E; Muller, A. L.; Moraes Flores, E. M; Wagner, R and da Rocha, J. B. (2013). A single consumption of high amounts of the Brazil nuts improves lipid profile of healthy volunteers. Journal of Nutrition and Metabolism, pp:653-785

Cordaro, M; Siracusa, R; Fusco, R; D'Amico, R; Peritore, A. F; Gugliandolo, E; Genovese, T; Scuto, M; Crupi, R; Mandalari, G; Cuzzocrea, S; Di Paola, R and Impellizzeri, D. (2020). Cashew (Anacardium occidentale L.) nuts counteract oxidative stress and inflammation in an acute experimental model of carrageenan - induced paw edema. Antioxidants (Basel, Switzerland), 9(8):660.

Das, Undurti. (2018). Arachidonic acid and other unsaturated fatty acids and some of their metabolites function as endogenous antimicrobial molecules. Journal of Advanced Research, 11:10-21.

Downs, M. L.; Baumert, J. L.; Taylor, S. L. and Mills, E. N. (2016). Mass spectrometric analysis of allergens in roasted walnuts. Journal of Proteomics, 142:62-69.

Dumont, E; Vanhaecke, F. and Cornelis, R. (2006). Selenium speciation from food source to metabolites: a critical review. Analytical and Bioanalytical Chemistry, 385(7):1304-1323.

FAO/WHO/UNU (2002). Protein and amino acid requirements in human nutrition. In: Report of a Joint FAO/WHO/UNU Expert Consultation, World Health Org. Tech. Report., No.935

Fatima, A; Chennupati, $\mathbf{H}$ and Aduri, P. (2020). Food and nutrition as natural immuneboosters: An elaborative review. IJISET, 7(6):112-119.

Fatima, T; Showkat, U and Hussain, S.Z. (2018). Nutritional and health benefits of walnuts. Journal of Pharmacognosy and Phytochemistry, 7:12691271 .

Fraser, G. E; Bennett, H. W; Jaceldo, K. B and Sabaté, J. (2002). Effect on body weight of a free 76 Kilojoule (320 calorie) daily supplement of almonds for six months. Journal of the American College of Nutrition, 21(3):275-283.

Gagliano, N; Aldini, G; Colombo, G; Rossi, R; Colombo, R; Gioia, M; Milzani, A and Dalle-Donne, I. (2010). The potential of resveratrol against human gliomas. Anticancer Drugs, 21(2):140-150.

Gajcy, K; Lochyñski, S and Librowski, T. (2010). A role of GABA analogues in the treatment of neurological diseases. Current Medicinal Chemistry, 17(22):2338-2347.

Gentile, C; Perrone, A; Attanzio, A; Tesoriere, L and Livrea, M. A. (2015). Sicilian pistachio (Pistacia vera L.) nut inhibits expression and release of inflammatory mediators and reverts the increase of paracellular permeability in IL-1 $\beta$-exposed human intestinal epithelial cells. European Journal of Nutrition, 54(5):811-821.

Gervasi, T.; Barreca, D.; Laganà, G. and Mandalari, G. (2021). Health benefits related to tree nut consumption and their bioactive compounds. International Journal of Molecular Sciences, 22(11):5960. 
Gombart, A. F; Pierre, A and Maggini, S. (2020). A review of micronutrients and the immune system-working in harmony to reduce the risk of infection. Nutrients, 12(1):236.

Grace, M. H; Esposito, D; Timmers, M. A; Xiong, J; Yousef, G; Komarnytsky, S and Lila, M. A. (2016). Chemical composition, antioxidant and antiinflammatory properties of pistachio hull extracts. Food Chemistry, 210:85-95.

Grant, W. B; Lahore, H; McDonnell, S. L; Baggerly, C. A; French, C. B; Aliano, J. L. and Bhattoa, H. P. (2020). Evidence that vitamin D supplementation could reduce risk of influenza and COVID-19 infections and deaths. Nutrients, 12(4):988.

Gulati, S; Misra, A; Pandey, R. M; Bhatt, S. P and Saluja, S. (2014). Effects of pistachio nuts on body composition, metabolic, inflammatory and oxidative stress parameters in Asian Indians with metabolic syndrome: A 24-wk, randomized control trial. Nutrition (Burbank, Los Angeles County, Calif.), 30(2):192-197.

Güne ${ }^{\circ}$, M; ${ }^{a}$ ahin, S; Demir, C; Borum, E and Tosunoðlu, A. (2017). Determination of phenolic compounds profile in chestnut and floral honeys and their antioxidant and antimicrobial activities. J. Food Biochem., 41(3): 12345 .

Gupta, S; Read, S. A; Shackel, N. A; Hebbard, L; George, J and Ahlenstiel, G (2019). The role of micronutrients in the infection and subsequent response to hepatitis C virus. Cells, 8(6):603.

Han, S. N; Wu, D; Ha, W. K; Beharka, A; Smith, D. E; Bender, B. S and Meydani, S. N. (2000). Vitamin E supplementation increases T helper 1 cytokine production in old mice infected with influenza virus. Immunology, 100(4):487-493.

Hayes, D; Angove, M. J; Tucci, J and Dennis, C. (2016). Walnuts (Juglans regia) chemical composition and research in human health. Critical Reviews in Food Science and Nutrition, 56(8):1231-1241.

He, X; Fang, J; Guo, Q; Wang, M; Li, Y; Meng, Y and Huang, L. (2020). Advances in antiviral polysaccharides derived from edible and medicinal plants and mushrooms. Carbohydrate Polymers, 229:1 15548.

Hemilä, H and Kaprio, J. (2008). Vitamin E supplementation and pneumonia risk in males who initiated smoking at an early age: Effect modification by body weight and dietary vitamin C. Nutrition Journal, 7:33

Hemila, $\mathbf{H}$ and Kaprio, J. (2011). Subgroup analysis of large trials can guide further research: A case study of vitamin E and pneumonia. Clin. Epidemiol., 3(1):51-59.

Huang, H. Y; Caballero, B; Chang, S; Alberg, A. J; Semba, R. ; Schneyer, C. R; Wilson, R. F; Cheng, T. Y; Vassy, J; Prokopowicz, G; Barnes, G. J 2nd and Bass, E. B. (2006). The efficacy and safety of multivitamin and mineral supplement use to prevent cancer and chronic disease in adults: A systematic review for a National Institutes of Health state-of-thescience conference. Annals of Internal Medicine, 145(5):372-385.

Huang, Z; Liu, Y; Qi, G; Brand, D and Zheng, S. G. (2018). Role of vitamin A in the immune system. Journal of Clinical Medicine, 7(9):258.

Hwang, H. J; Han, J. W; Jeon, H; Cho, K; Kim, J. H; Lee, D. S and Han, J. W. (2020). Characterization of a novel mannose-binding lectin with antiviral activities from red alga, Grateloupia-chiangii. Biomolecules, 10(2):333.

Ijarotimi, O. S; Oluwalana, I. B and Ogunedojutimi, M. O. (2012). "Nutrient composition, functional, sensory and microbial status of popcorn based (Zea may Everta) complementary foods enriched with cashew nut (Anacardium occidentale L.) flour". Afr. J. Food Agri. Nutri. Dev., 12(5):6424-6446.

Indhuleka, A; Sanjana, R; Janet, J and Ragavi. V. (2020). Importance of vegetables as healthier diet in the management of COVID-19 pandemic. Annals of Phytomedicine: An International Journal, 9(2):62-79.
Jambazian, P. R; Haddad, E; Rajaram, S; Tanzman, J and Sabaté, J. (2005). Almonds in the diet simultaneously improve plasma alphatocopherol concentrations and reduce plasma lipids. Journal of the American Dietetic Association, 105(3):449-454.

Jamshidi, S; Moradi, Y; Nameni, G; Mohsenpour, M.A and Vafa, M. (2021). Effects of cashew nut consumption on body composition and glycemic indices: A meta-analysis and systematic review of randomized controlled trials. Diabetes and Metabolic Syndrome: Clinical Research and Reviews, 15(2):605-613.

Jarosz, M; Olbert, M; Wyszogrodzka, G; Mlyniec, K and Librowski, T. (2017). Antioxidant and anti-inflammatory effects of zinc. Zinc-dependent $\mathrm{NF}-\kappa$ Bsignaling. Inflammopharmacol., 25(1):11-24.

Jayawardena, R; Sooriyaarachchi, P; Chourdakis, M; Jeewandara and Ranasinghe, P. (2020). Enhancing immunity in viral infections, with special emphasis on COVID-19: A review. Diabetes and Metabolic Syndrome, 14(4):367-382.

Jeandet, P; Delaunois, B; Aziz, A; Donnez, D; Vasserot, Y; Cordelier, S and Courot, E. (2012). Metabolic engineering of yeast and plants for the production of the biologically active hydroxystilbene, resveratrol. Journal of Biomedicine and Biotechnology, 2012:579089.

Jesch, E. D and Carr, T. P. (2017). Food ingredients that inhibit cholesterol absorption. Preventive Nutrition and Food Science, 22(2):67-80.

Jiang, C; Wang, Z; Ganther, H. and Lu, J. (2001). Caspases as key executors of methyl selenium-induced apoptosis (anoikis) of DU-145 prostate cancer cells. Cancer Research, 61(7):3062-3070.

Jiang, W; Oken, H; Fiuzat, M; Shaw, L.K; Martsberger, C; Kuchibhatla, M; KaddurahDaouk, R; Steffens, D.C; Baillie, R; Cuffe, M; Krishnan, R and O'Connor, C. (2012). Plasma omega-3 polyunsaturated fatty acids and survival in patients with chronic heart failure and major depressive disorder. Journal of Cardiovascular Translational Research, 5(1):92-99.

Jolliffe, D. A; Griffiths, C. J and Martineau, A. R. (2013). Vitamin D in the prevention of acute respiratory infection: Systematic review of clinical studies. The Journal of Steroid Biochemistry and Molecular Biology, 136:321-329.

Karacabey, K and N. Ozdemir. (2020). "The effect of nutritional elements on the immune system." J. Obes. Wt Loss Ther., 2:152.

Karppi, J., Nurmi, T; Kurl, S; Rissanen, T. H and Nyyssönen, K. (2010). Lycopene, lutein and beta-carotene as determinants of LDL conjugated dienes in serum. Atherosclerosis, 209(2):565-572.

Kashaninejad, M. and Tabil, L.G. (2011). Pistachio (Pistacia vera L.). In postharvest biology and technology of tropical and subtropical fruits: Volume 4: Mangosteen to white sapote. Woodhead Publishing Ltd., Cambridge, U.K, pp:218-246.

Kieliszek, M. (2019). Selenium-fascinating microelement, Properties and sources in food. Molecules, 24(7):1298.

Kim, J. K; Cho, M. L; Karnjanapratum, S; Shin, I. S and You, S. G. (2011). In vitro and in vivo immunomodulatory activity of sulfated polysaccharides from rnteromorphaprolifera. International Journal of Biological Macromolecules, 49(5):1051-1058.

Kim, Y; Kim, H; Bae, S; Choi, J; Lim, S. Y; Lee, N; Kong, J. M; Hwang, Y. I; Kang, J. $\mathbf{S}$ and Lee, W. J. (2013). Vitamin $\mathrm{C}$ is an essential factor on the antiviral immune responses through the production of interferon- $\alpha / \beta$ at the initial stage of influenza $A$ virus $\left(\mathrm{H}_{3} \mathrm{~N}_{2}\right)$ infection. Immune Network, 13(2):70-74.

King, J. C; Blumberg, J; Ingwersen, L; Jenab, M andTucker, K. L. (2008). Tree nuts and peanuts as components of a healthy diet. The Journal of Nutrition, 138(9):1736-1740. 
Klotman, M and Chang, T. (2006). Defensins in innate antivira immunity. Nat. Rev. Immunol., 6:447-456.

Kumar, V. P; Prashanth, K and Venkatesh, Y. P. (2015). Structural analyses and immunomodulatory properties of fructo-oligosaccharides from onion (Allium cepa). Carbohydrate Polymers, 117:115-122.

L.C, De. (2020). Edible seeds and nuts in human diet for immunity development. Intl. J. Recent. Sci. Res., 11(6):38877-38881.

Lee, G. Y and Han, S. N. (2018). The role of vitamin E in immunity. Nutrients, 10(11): 1614 .

Leung, M. Y; Liu, C; Koon, J. C and Fung, K. P. (2006). Polysaccharide biological response modifiers. Immunology Ketters, 105(2):101-114.

Leung, WK; To, KF ; Chan, PK; Chan, HL; Wu, AK ; Lee, N; Yuen, K. Y and Sung, J. J. (2003). Enteric involvement of severe acute respiratory syndrome associated coronavirus infection. Gastroenterology, 125(4):10111017.

Li, S. C; Liu, Y. H.; Liu, J. F.; Chang, W. H.; Chen, C. M. and Chen, C. Y. (2011) Almond consumption improved glycemic control and lipid profiles in patients with type 2 diabetes mellitus. Metabolism: Clinical and Experimental, 60(4):474-479.

Lin, M. H; Moses, D. C; Hsieh, C. H; Cheng, S. C; Chen, Y.H; Sun, C. Y and Chou, C Y. (2018). Disulfiram can inhibit MERS and SARS coronavirus papainlike proteases via different modes. Antiviral Research, 150:155163

Liu, Z; Lin, X; Huang, G; Zhang, W; Rao, P and Ni, L. (2014). Prebiotic effects of almonds and almond skins on intestinal microbiota in healthy adult humans. Anaerobe, 26:1-6.

Lopes, R. M; Agostini-Costa, T; Gimenes, M. A and Silveira, D. (2011). Chemical composition and biological activities of Arachis species. Journal of Agricultural and Food Chemistry, 59(9):4321-4330.

Luo, H; Tang, Q. L; Shang, Y. X; Liang, S. B; Yang, M; Robinson, N and Liu, J. P. (2020). Can Chinese medicine be used for prevention of corona virus disease 2019 (COVID-19)? A review of historical classics, research evidence and current prevention programs. Chinese Journal of Integrative Medicine, 26(4):243-250.

Ma, X; Bi, S; Wang, Y; Chi, X and Hu, S. (2019). Combined adjuvant effect of ginseng stem-leaf saponins and selenium on immune responses to a live bivalent vaccine of newcastle disease virus and infectious bronchitis virus in chickens. Poultry Science, 98(9):3548-3556.

Ma, Y; Njike, V.Y.; Millet, J.; Dutta, S.; Doughty, K.; Treu, J.A. and Katz, D. L. (2010). Effects of walnut consumption on endothelial function in type 2 diabetic subjects: A randomized controlled crossover trial. Diabetes Care, 33(2):227-232.

Maares, $M$ and Haase, H. (2016). Zinc and immunity: An essential interrelation. Archives of Biochemistry and Biophysics, 611:5865 .

Mao, R; Wu, L; Zhu, N; Liu, X; Hao, Y; Liu, R; Du, Q and Li, Y. (2020) Immunomodulatory effects of walnut (Juglans regia L.) oligopeptides on innate and adaptive immune responses in mice. Journal of Functional Foods, 73:104068.

Marquardt, ML; Done, SL; Sandrock, M; Berdon WE and Feldman, KW. (2012) "Copper deficiency presenting as metabolic bone disease in extremely low birth weight, short-gut infants", Pediatrics, 130(3):695-698

Martínez-Ballesta, M.C; Dominguez-Perles, R; Moreno, D.A.; Muries, B; AlcarazLopez, C; Bastias, E; Garcia-Viguera, C and Carvajal, M. (2010). Minerals in plant food: Effect of agricultural practices and role in human health. A review. Agronomy for Sustainable Development 30:295309
Mason R. J. (2020). Pathogenesis of COVID-19 from a cell biology perspective. The European Respiratory Journal, 55(4):200-607.

Méplan, C. and Hesketh, J. (2014). Selenium and cancer: A story that should not be forgotten-insights from genomics. Cancer Treatment and Research, 159:145-166.

Meydani, S. N; Barklund, M. P; Liu, S; Meydani, M; Miller, R. A; Cannon, J. G; Morrow, F. D; Rocklin, R and Blumberg, J. B. (1990). Vitamin E supplementation enhances cell-mediated immunity in healthy elderly subjects. The American Journal of Clinical Nutrition, 52(3):557563.

Meydani, S. N; Leka, L. S; Fine, B. C; Dallal, G. E; Keusch, G. T; Singh, M. F and Hamer, D. H. (2004). Vitamin E and respiratory tract infections in elderly nursing home residents: A randomized controlled trial. JAMA, 292(7):828-836.

Micha, R and Mozaffarian, D. (2010). Saturated fat and cardiometabolic risk factors, coronary heart disease, stroke, and diabetes: A fresh look at the evidence. Lipids, 45(10):893-905.

Mullin, G. E. (2011). Vitamin A and immunity. Nutrition in Clinical Practice, 26(4):495-496

Okuda T. (2005). Systematics and health effects of chemically distinct tannins in medicinal plants. Phytochemistry, 66(17): 2012-2031.

Park, J. E and Gallagher, T. (2017). Lipidation increases antiviral activities of coronavirus fusion-inhibiting peptides. Virology, 511:9-18.

Parkar, S. G; Stevenson, D. E and Skinner, M. A. (2008). The potential influence of fruit polyphenols on colonic microflora and human gut health. International Journal of Food Microbiology, 124(3):295-298.

Paules, CI; Marston, HD and Fauci, AS. (2020). Coronavirus infections-more than just the common cold. JAMA., 323(8):707-708.

Pereira, M. A; Rebouças, J. S; Ferraz-Carvalho, R. S; de Redín, I. L; Guerra, P. V; Gamazo, C; Brodskyn, C. I; Irache, J. M and Santos-Magalhães, N. S. (2018). Poly (anhydride) nanoparticles containing cashew nut proteins can induce a strong Th1 and Treg immune response after oral administration. European Journal of Pharmaceutics and Biopharmaceutics, 127:51-60.

Powers H. J. (2003). Riboflavin (vitamin B-2) and health. The American Journal of Clinical Nutrition, 77(6):1352-1360.

Reboul, E. (2017). Vitamin E bioavailability: Mechanisms of intestinal absorption in the spotlight. Antioxidants, 6(4):95.

Ros E. (2010). Health benefits of nut consumption. Nutrients, 2(7):652682.

Sabater-Molina, M; Larqué, E; Torrella, F and Zamora, S. (2009). Dietary fructooligosaccharides and potential benefits on health. Journal of Physiology and Biochemistry, 65(3):315-328.

Sapkota, K; park, S.E; kim, J.E; kim, S; choi, H.S; chun H.S and kim, S.J. (2010). Antioxidant and antimelanogenic properties of chestnut flower extract. Bioscience, Biotechnology, and Biochemistry, 74:8:1527-1533

Satýl, F; Azcan, N and Baper, K. (2004). Fatty acid composition of pistachio nuts in Turkey. Chemistry of Natural Compounds, 39:322-324.

aen, S.M and Karadeniz, T. (2015). The nutritional value of walnut. Journal of Hygienic Engineering and Design, 11:68.

Shakoor, H; Feehan, J; Al Dhaheri, A. S; Ali, H. I; Platat, C; Ismail, L. C Apostolopoulos, V and Stojanovska, L. (2021). Immune-boosting role of vitamins D, C, E, zinc, selenium and omega-3 fatty acids: Could they help against COVID-19?. Maturitas, 143:1-9.

Singh, R. S; Walia, A. K and Kennedy, J. F. (2020). Mushroom lectins in biomedical research and development. International Journal of Biological Macromolecules, 151:1340-1350. 
Skalny, A. V; Rink, L; Ajsuvakova, O. P; Aschner, M; Gritsenko, V. A; Alekseenko, S. I; Svistunov, A. A; Petrakis, D; Spandidos, D. A; Aaseth, J; Tsatsakis, A and Tinkov, A. A. (2020). Zinc and respiratory tract infections: Perspectives for COVID-19 (Review). International Journal of Molecular Medicine, 46(1):17-26.

Smoliga, J. M; Baur, J. A and Hausenblas, H. A. (2011). Resveratrol and health: A comprehensive review of human clinical trials. Molecular Nutrition and Food Research, 55(8):1129-141.

Song, Y; Ridker, P. M; Manson, J. E; Cook, N. R; Buring, J. E and Liu, S. (2005) Magnesium intake, C-reactive protein, and the prevalence of metabolic syndrome in middle-aged and older U.S. women. Diabetes Care, 28(6): 1438-1444.

Souza, R. G.; Gomes, A. C.; Naves, M. M. and Mota, J. F. (2015). Nuts and legume seeds for cardiovascular risk reduction: Scientific evidence and mechanisms of action. Nutrition Reviews, 73(6):335-347.

Souza, R.; Schincaglia, R. M.; Pimentel, G. D. and Mota, J. F. (2017). Nuts and human health outcomes: A systematic review. Nutrients, 9(12):1311.

Sudheer, A. R; Muthukumaran, S; Devipriya, N and Menon, V. P. (2007). Ellagic acid, a natural polyphenol protects rat peripheral blood lymphocytes against nicotine-induced cellular and DNA damage in vitro, with the comparison of N-acetylcysteine. Toxicology, 230(1):11-21.

Tapsell, L. C; Gillen, L. J; Patch, C. S; Batterham, M; Owen,A; Baré, M and Kennedy M. (2004). Including walnuts in a low-fat/modified-fat diet improves HDL cholesterol-to-total cholesterol ratios in patients with type 2 diabetes. Diabetes Care, 27(12):2777-2783.

Terzo, S; Baldassano, S; Caldara, G. F; Ferrantelli, V; Lo Dico, G; Mulè, F and Amato, A. (2019). Health benefits of pistachios consumption. Natural Product Research, 33(5):715-726.

Thirumdas, R; Kothakota, A; Pandiselvam, R; Bahrami, A and Barba, F. J. (2021) Role of food nutrients and supplementation in fighting against viral infections and boosting immunity: A review. Trends in Food Science and Technology, 110:66-77.

Tufail, T; Saeed, F; Ul Ain, H. B; Niaz, B; Afzaal, M; Din, A and RasulSuleria, H. A (2019). Cashew nut allergy; immune health challenge. Trends in Food Science and Technology, 86:209-216.

Turnlund, JR; Jacob, RA; Keen, CL; Strain, JJ; Kelley, DS; Domek, JM; Keyes, WR; Ensunsa, JL; Lykkesfeldt, J and Coulter, J. (2004). Long-term high copper intake: Effects on indexes of copper status, antioxidant status, and immune function in young men. The American Journal of Clinical Nutrition, 79(6): 1037-1044.

United States Department of Agriculture (USDA) http://ndb.nal.usda. gov/ndb/ foods $/$ show $/ 4800 ? \mathrm{fgcd}=\& \mathrm{manu}=\& 1$ facet $=\&$ format $=\&$ count $=\& \max =35 \&$ offset $=\&$ sort $=\& q$ lookup $=$ peanut. Accessed $15 \mathrm{Apr}$. 2015 .

Urbancikova, I; Hudackova, D; Majtan, J; Rennerova, Z; Banovcin, P and Jesenak, M. (2020). Efficacy of pleuran ( $\beta$-glucan from Pleurotus ostreatus in the management of herpes simplex virus type 1 infection. Evidence-based Complementary and Alternative Medicine, 8562309 .

Vasconcelos, M. C; Bennett, R. N; Rosa, E. A and Ferreira-Cardoso, J. V. (2010) Composition of European chestnut (Castanea sativa Mill.) and association with health effects: Fresh and processed products. Journal of the Science of Food and Agriculture, 90(10):1578-1589.

Venkatachalam, M and Sathe, S. K. (2006). Chemical composition of selected edible nut seeds. Journal of Agricultural and Food Chemistry, 54(13):4705-4714.
Vincent, M; Duval, R. E; Hartemann, P and Engels-Deutsch, M. (2018). Contact killing and antimicrobial properties of copper. Journal of Applied Microbiology, 124(5):1032-1046.

Vyavahare, R.D; Khuspe, P; Mandhare, T; Kashid, P; Kakade, V.S; Raghuraman, V and Otari, K.V. (2020). Health benefit of a handful of cashew nuts (Anacardium occidentale L.) to prevent different disorders like diabetes, heart disorders, cancer, weight gain, gallstone, migraine headache. Journal of Pharmaceutical Quality Assurance and Quality Control, 2(1):10-18.

Wakabayashi, H; Oda, H; Yamauchi, K and Abe, F. (2014). Lactoferrin for prevention of common viral infections. Journal of infection and chemotherapy: Official journal of the Japan Society of Chemotherapy, 20(11):666-671.

Wang, D; Hu, B; Hu, C; Zhu, F; Liu, X; Zhang, J; Wang, B; Xiang, H; Cheng, Z; Xiong, Y; Zhao, Y; Li, Y; Wang, X and Peng, Z (2020). Clinical characteristics of 138 hospitalized patients with 2019 novel coronavirus-infected pneumonia in Wuhan, China. JAMA, 323(11):1061-1069.

Wani, I. A; Hamid, H; Hamdani, A. M; Gani, A and Ashwar, B. A. (2017). Physicochemical, rheological and antioxidant properties of sweet chestnut (Castanea sativa Mill.) as affected by pan and microwave roasting. Journal of Advanced Research, 8(4):399-405.

Wessels, I; Maywald, M and Rink, L. (2017). Zinc as a gatekeeper of immune function. Nutrients, 9(12):1286.

Wessling-Resnick M. (2018). Crossing the iron gate: Why and how transferrin receptors mediate viral entry. Annual Review of Nutrition, 38:431-458.

Wien, M. A; Sabaté, J. M; Iklé, D. N; Cole, S. E and Kandeel, F. R. (2003). Almonds vs complex carbohydrates in a weight reduction program. International Journal of Obesity and Related Metabolic Disorders : Journal of the International Association for the Study of Obesity, 27(11):1365-1372.

Willis, L. M; Shukitt-Hale, B; Cheng, V and Joseph, J. A. (2009). Dose-dependent effects of walnuts on motor and cognitive function in aged rats. The British Journal of Nutrition, 101(8):1140-1144.

Wong, J. M; de Souza, R; Kendall, C. W; Emam, A and Jenkins, D. J. (2006). Colonic health: Fermentation and short chain fatty acids. Journal of Clinical Gastroenterology, 40(3):235-243.

Wu, B; Capilato, J; Pham, M. P; Walker, J; Spur, B; Rodriguez, A; Perez, L. J and Yin, K. (2016). Lipoxin A4 augments host defense in sepsis and reduces Pseudomonas aeruginosa virulence through quorum sensing inhibition. FASEB Journal : Official Publication of the Federation of American Societies for Experimental Biology, 30(6):2400-2410.

Wu, D; Lewis, E. D; Pae, M and Meydani, S. N. (2019). Nutritional modulation of immune function: Analysis of evidence, mechanisms, and clinical relevance. Frontiers in Immunology, 9:3160.

Yang, C.; Yang, X.; Du, J.; Wang, H.; Li, H.; Zeng, L.; Gu, W. and Jiang, J. (2015). Retinoic acid promotes the endogenous repair of lung stem/ progenitor cells in combined with simvastatin after acute lung injury: A stereological analysis. Respir. Res., 16:140.

Yang, J. (2009). Brazil nuts and associated health benefits: A review. LWT Food Science and Technology, 42(10):1573-1580.

Yi, M; Fu, J; Zhou, L; Gao, H; Fan, C; Shao, J; Xu, B; Wang, Q; Li, J; Huang, G; Lapsley, K; Blumberg, J. B and Chen, C. Y. (2014). The effect of almond consumption on elements of endurance exercise performance in trained athletes. Journal of the International Society of Sports Nutrition, 11:18. 